\title{
Isothermal melt-crystallization and melting behavior for three linear aromatic polyesters
}

\author{
Nujalee Dangseeyun, Phornphon Srimoaon, Pitt Supaphol*, Manit Nithitanakul \\ The Petroleum and Petrochemical College, Chulalongkorn University, Soi Chula 12, Phyathai Road, Pathumwan, Bangkok 10330, Thailand
}

Received 26 February 2003; received in revised form 16 June 2003; accepted 16 June 2003

\begin{abstract}
Isothermal crystallization and subsequent melting behavior for three different types of linear aromatic polyester, namely poly(ethylene terephthalate) (PET), poly(trimethylene terephthalate) (PTT), and poly(butylene terephthalate) (PBT), were investigated (with an emphasis on PTT in comparison with PET and PBT). These polyesters were different in the number of methylene groups (i.e. 2, 3, and 4 for PET, PTT, and PBT, respectively). Isothermal crystallization studies were carried out in a differential scanning calorimeter (DSC) over the crystallization temperature range of $182-208^{\circ} \mathrm{C}$. The wide-angle X-ray diffraction (WAXD) technique was used to obtain information about crystal modification and apparent degree of crystallinity. The kinetics of the crystallization process was assessed by a direct fitting of the experimental data to the Avrami, Tobin, and Malkin macrokinetic models. It was found that the crystallization rates of these polyesters were in the following order: PBT > PTT > PET, and the melting of these polyesters exhibited multiple-melting phenomenon. Lastly, the equilibrium melting temperature for these polyesters was estimated based on the linear and non-linear Hoffman-Weeks (LHW and NLHW) extrapolative methods. (C) 2003 Elsevier B.V. All rights reserved.
\end{abstract}

Keywords: Poly(ethylene terephthalate); Poly(trimethylene terephthalate); Poly(butylene terephthalate); Crystallization kinetics; Melting behavior; Equilibrium melting temperature

\section{Introduction}

In 1941, a new type of linear aromatic polyester, poly(trimethylene terephthalate) (PTT), was successfully synthesized [1], but it was not commercially available then because of the cost of 1,3-propanediol, one of the raw materials used to produce PTT. With a breakthrough in the synthesis of 1,3-propanediol at a much lower price, PTT is now commercially available and has been produced by Shell Chemicals under the tradename Corterra, joining the rank of other linear aromatic polyesters, poly(ethylene terephthalate) (PET) and poly(butylene terephthalate) (PBT). PTT has properties in between those of PET and PBT, with an unusual combination of the outstanding properties of PET and processing characteristics of PBT. These make PTT highly suitable for uses in fiber, film and engineering thermoplastic applications.

PTT has three methylene units in its chemical structure, rendering PTT chains to be more flexible. Hence, PTT

\footnotetext{
* Corresponding author. Tel.: +66-2-218-4134; fax: +66-2-215-4459.

E-mail address: pitt.s@chula.ac.th (P. Supaphol).
}

displays a greater crystallization rate than does PET. The glass-transition and the apparent melting temperatures of PTT were reported to be ca. 44 and $228^{\circ} \mathrm{C}$ [2], respectively. Like PET and PBT, PTT crystallizes in a triclinic crystal structure, with the periodicity along the $c$-axis containing two repeating units and the methylene groups being arranged in a highly contracted gauche-gauche conformation [3].

Recently, the overall crystallization kinetics of PTT have been studied [4]. The analysis was based on the Avrami proposition. It was found that, at a given degree of undercooling, the crystallization rate of PTT lies between those of PET and PBT. PBT has the highest crystallization rates with the Avrami rate constant $\left(k_{\mathrm{a}}\right)$ being in the order of $10^{-2}$ to $10^{-1} \min ^{-n}$, which is approximately an order of magnitude greater than that for PTT at $10^{-3}$ to $10^{-2} \mathrm{~min}^{-n}$, which, in turn, is about an order of magnitude greater than that for PET at $10^{-4}$ to $10^{-2} \mathrm{~min}^{-n}$. Similar results have been reported elsewhere [2].

The multiple-melting phenomenon upon subsequent melting of isothermally crystallized PTT samples in a differential scanning calorimeter (DSC) has recently been reported [5]. This phenomenon was attributed to the dual populations of lamellar stacks formed during primary crystallization and 
recrystallization during subsequent heating process. Based on wide-angle X-ray diffraction (WAXD) results, it was suggested that the crystal modification of PTT did not change with crystallization temperature, at least within the temperature range studied [5].

The overall isothermal crystallization and subsequent melting behavior of PTT in critical comparison with those of PET and PBT, based mainly on results obtained from DSC and WAXD techniques are reported herein. The isothermal crystallization data have been analyzed based on various mathematical models, namely the Avrami, Tobin, and Malkin macrokinetic models. The equilibrium melting temperatures of PTT, PET and PBT are also evaluated based on both linear and non-linear Hoffman-Weeks (LHW and NLHW) extrapolations.

\section{Theoretical background}

Isothermal bulk crystallization kinetics of semi-crystalline polymers in a DSC is usually studied by following the crystallization exotherms [6,7], based on the assumption that the evolution of crystallinity is linearly proportional to the evolution of heat released during the course of crystallization. Based on this notion, the relative crystallinity as a function of time $\theta(t)$ can be obtained according to the following equation:

$\theta(t)=\frac{\int_{0}^{t}\left(\mathrm{~d} H_{\mathrm{c}} / \mathrm{d} t\right) \mathrm{d} t}{\int_{0}^{\infty}\left(\mathrm{d} H_{\mathrm{c}} / \mathrm{d} t\right) \mathrm{d} t} \in[0,1]$,

where $t$ and $\infty$ are the elapsed time during the course of crystallization and at the end of crystallization process, respectively, and $\mathrm{d} H_{\mathrm{c}}$ is the enthalpy of crystallization during an infinitesimal time interval $\mathrm{d} t$.

In order to quantitatively describe the macroscopic evolution of crystallinity during primarily crystallization under quiescent isothermal conditions, a number of macrokinetic models have been proposed over the past 60 years. They are, for examples, the so-called 'Avrami' [8-13], Tobin [14-16], and Malkin [17] models. In the Avrami model [8-13], the relative crystallinity as a function of time $\theta(t)$ is related to the crystallization time $t$ according to the equation:

$\theta(t)=1-\exp \left[-\left(K_{\mathrm{a}} t\right)^{n_{\mathrm{a}}}\right] \in[0,1]$,

where $K_{\mathrm{a}}$ and $n_{\mathrm{a}}$ are the Avrami crystallization rate constant and the Avrami exponent, respectively. Usually, $K_{\mathrm{a}}$ is written in the form of the composite Avrami rate constant $k_{\mathrm{a}}$ (i.e. $k_{\mathrm{a}}=K_{\mathrm{a}}^{n}$ ). Since the units of $k_{\mathrm{a}}$ are a function of $n_{\mathrm{a}}$, use of $K_{\mathrm{a}}$ should be more preferable since its units are given in (time) $)^{-1}$ [18]. Both $K_{\mathrm{a}}$ and $n_{\mathrm{a}}$ are constants specific to a given crystalline morphology and type of nucleation for a particular crystallization condition [19] and that based on the original assumptions of the theory, the value of $n_{\mathrm{a}}$ should be an integer ranging from 1 to 4 .

To improve the Avrami equation in describing the observed behavior during the later stages of crystallization,
Tobin [14-16] proposed a different expression to describe the kinetics of phase transformation by taking into account the growth impingement. The original theory was written in the form of a non-linear Volterra integral equation, of which the zeroth order solution is given by

$\theta(t)=\frac{\left(K_{\mathrm{t}} t\right)^{n_{\mathrm{t}}}}{1+\left(K_{\mathrm{t}} t\right)^{n_{\mathrm{t}}}} \in[0,1]$

where $K_{\mathrm{t}}$ is the Tobin rate constant, and $n_{\mathrm{t}}$ the Tobin exponent. Based on this proposition, the Tobin exponent needs not be integral [14-16], and it is mainly governed by different types of nucleation and growth mechanisms. According to the original publications [14-16], $K_{\mathrm{t}}$ is written in the form of the composite Tobin rate constant $k_{\mathrm{t}}$ (i.e. $k_{\mathrm{t}}=K_{\mathrm{t}}^{n}$ ). Similar to the case of $k_{\mathrm{a}}$, the units of $k_{\mathrm{t}}$ are a function of $n_{\mathrm{t}}$, therefore use of $K_{\mathrm{t}}$ should be more preferable since its units are given in (time) $)^{-1}$.

Derived based on a postulation that the overall crystallization rate equals the summation of the rate at which the degree of crystallinity varies with the emergence of primary nuclei and the rate of variation in the degree of crystallinity varies with crystal growth rate, a totally different kinetic equation may be obtained [17]:

$\theta(t)=1-\frac{C_{0}+1}{C_{0}+\exp \left(C_{1} t\right)} \in[0,1]$,

where $C_{0}$ is the Malkin exponent which is directly related to the ratio of the crystal growth rate $G$ to the primary nucleation rate $I$ (i.e. $C_{0} \alpha G / I$ ), and $C_{1}$ is the Malkin crystallization rate constant which is directly related to overall crystallization (i.e. $C_{1}=a G+b I$, where $a$ and $b$ are some specific constants). The units of $C_{1}$ are given in $(\text { time })^{-1}$.

\section{Experimental details}

\subsection{Materials}

Poly(trimethylene terephthalate) was supplied in pellet form by Shell Chemicals (USA) (Corterra CP509201). The weight- and number-average molecular weights of this resin were determined to be ca. 78,100 and $34,700 \mathrm{Da}$, respectively. Poly(ethylene terephthalate) was supplied in pellet form by Indo PET (Thailand) (N1). The weight- and number-average molecular weights of this resin were determined to be ca. 84,500 and $41,200 \mathrm{Da}$, respectively. Finally, poly(butylene terephthalate) was supplied in pellet form by LG Chem (Korea) (LUPOX GP-2000). The weight- and number-average molecular weights of this resin were determined to be ca. 71,500 and $36,300 \mathrm{Da}$, respectively. It should be noted that molecular weight characterization of these resins was carried out by Dr. Chuah and co-workers of Shell Chemicals (USA) based on size-exclusion chromatography (SEC). 


\subsection{Sample preparation}

PET, PTT and PBT resins were dried in a vacuum oven at $140^{\circ} \mathrm{C}$ for $5 \mathrm{~h}$ prior to further use. Films of ca. $200 \mu \mathrm{m}$ in thickness were melt-pressed at $280^{\circ} \mathrm{C}$ for PET and $260^{\circ} \mathrm{C}$ for PTT and PBT in a Wabash V50H compression molding machine under an applied pressure of $4.62 \times 10^{2}$ $\mathrm{MN} \mathrm{m}^{-2}$. After $5 \mathrm{~min}$ holding time, the films were taken out and allowed to cool, under ambient conditions, to room temperature between the two metal platens. This treatment assures that previous thermo-mechanical history was essentially erased, and provided a standard crystalline memory condition for the as-prepared film.

\subsection{Differential scanning calorimetry measurements}

A DSC (DSC-7, Perkin-Elmer) was used to record isothermal crystallization exotherms and subsequent melting endotherms of these polyester resins. Calibration for the temperature scale was carried out using a pure indium standard $\left(T_{\mathrm{m}}^{0}=156.6^{\circ} \mathrm{C}\right.$ and $\left.\Delta H_{\mathrm{f}}^{0}=28.5 \mathrm{~J} \mathrm{~g}^{-1}\right)$ on every other run to ensure accuracy and reliability of the data obtained. To minimize thermal lag between the polymer sample and DSC furnace, each sample holder was loaded with a disc-shape sample weighing around $8.0 \pm 0.5 \mathrm{mg}$ which was cut from the as-prepared films. Each sample was used only once and all the runs were carried out under nitrogen atmosphere to prevent extensive thermal degradation.

Each measurement started with heating each sample from $40^{\circ} \mathrm{C}$ at a heating rate of $80^{\circ} \mathrm{C} \mathrm{min}^{-1}$ to a desired melt-annealing temperature $T_{\mathrm{f}}$ (i.e. at $280^{\circ} \mathrm{C}$ for PET and $260^{\circ} \mathrm{C}$ for PTT and PBT, respectively). To ensure complete melting, the sample was kept at the respective $T_{\mathrm{f}}$ for a melt-annealing period of $5 \mathrm{~min}$. After this period, each sample was rapidly cooled (i.e. ca. $200^{\circ} \mathrm{C} \mathrm{min}^{-1}$ ) from $T_{\mathrm{f}}$ to a desired crystallization temperature, where it was held for the completion of the crystallization process (achievable when no significant change in the heat flow as a function of time was further observed). Both the isothermal crystallization exotherms and subsequent melting endotherms were recorded for further analysis. The heating rate used to record all of the subsequent melting endotherms was $10{ }^{\circ} \mathrm{C} \mathrm{min}^{-1}$. The kinetics of the isothermal crystallization process was carried out by directly fitting the experimental data to the aforementioned macrokinetic models.

\subsection{Crystal structure and crystallinity measurements}

Wide-angle X-ray diffraction was employed to determine crystal modification and apparent degree of crystallinity of PTT samples prepared in the conditions set forth for samples prepared for the DSC measurements (viz. after the samples were completely crystallized at a desired crystallization temperature, they were immediately quenched, without subsequent heating, to $30^{\circ} \mathrm{C}$ ). Each sample was then taken out of the DSC sample holder and was pasted onto a glass X-ray sample holder, using vasaline as adhesive. The WAXD intensity pattern of each sample was then collected on a Rigaku Rint 2000 diffractometer, equipped with a computerized data collection and analytical tools. The X-ray source $(\mathrm{Cu} \mathrm{K} \alpha$ radiation, $\lambda=1.54 \AA$ ) was generated with an applied voltage of $40 \mathrm{kV}$ and a filament current of $30 \mathrm{~mA}$.

\section{Results and discussion}

\subsection{Isothermal crystallization of polyesters from the melt}

Fig. 1 illustrates the time-dependent relative crystallinity function $\theta(t)$ (after subtraction of the induction period $t_{0}$ ) of PTT samples crystallized at two different temperatures (i.e. 184 and $194^{\circ} \mathrm{C}$, respectively). The raw data are shown in Fig. 1 using different geometrical symbols to represent data points. Evidently, within the temperature range studied, the time to reach the ultimate crystallinity (i.e. complete crystallization) increased with increasing crystallization temperature $T_{\mathrm{c}}$. An important bulk or overall crystallization kinetic parameter which can be determined directly from the $\theta(t)$ data is the half-time of crystallization $t_{0.5}$, defined as the elapsed time from the onset of crystallization to the point where the crystallization is half-completed. Table 1 summarizes the $t_{0.5}$ values taken from all of the experimental data obtained.

From the data displayed in Table 1, it is apparent that, for each resin, the $t_{0.5}$ value increased exponentially with increasing $T_{\mathrm{c}}$ (at least within the $T_{\mathrm{c}}$ range studied). Comparison of crystallization kinetics for these polyesters, which have different practical crystallization windows over the absolute temperature scale (i.e. $T_{\mathrm{g}}<T_{\mathrm{c}}<T_{\mathrm{m}}^{0}$ ), can be carried out by plotting the kinetic parameters versus the degree of undercooling $\Delta T$, which is defined as the difference between the equilibrium melting temperature $T_{\mathrm{m}}^{0}$ and the $T_{\mathrm{c}}$ (i.e. $\Delta T=T_{\mathrm{m}}^{0}-T_{\mathrm{c}}$ ). It should be noted that the $\Delta T$ reflects the driving force for crystallization and the $T_{\mathrm{m}}^{0}$ values for PET, PTT, and PBT have been determined by the linear Hoffman-Weeks extrapolation to be ca. 270.1, 243.6, and $235.4{ }^{\circ} \mathrm{C}$, respectively (see later).

Plots of $t_{0.5}$ values versus $\Delta T$ for all of the resins studied (not shown) exhibited increased $t_{0.5}$ values with decreasing $\Delta T$ (or with increasing $T_{\mathrm{c}}$ ). For a given $\Delta T$, PBT exhibited the lowest $t_{0.5}$ value, followed by those of PTT and PET, respectively. The results clearly suggested that crystallization proceeded at a much faster rate with increasing $\Delta T$ (or with decreasing $T_{\mathrm{c}}$ ) and that PBT crystallized at the greatest rate, followed by PTT and PET, respectively. Fig. 2 displays the reciprocal half-times of crystallization $t_{0.5}^{-1}$ versus $\Delta T$ for all of the polyesters studied. This type of plot is regarded as the most fundamental representation of the bulk crystallization rate for a semi-crystalline polymer. From Fig. 2, it is evident that all of the polymers studied exhibited increased $t_{0.5}^{-1}$ values with increasing $\Delta T$ (or with decreasing $T_{\mathrm{c}}$ ). For example, at $\Delta T=50 \mathrm{~K}$, the $t_{0.5}^{-1}$ values for PBT, PTT, and 


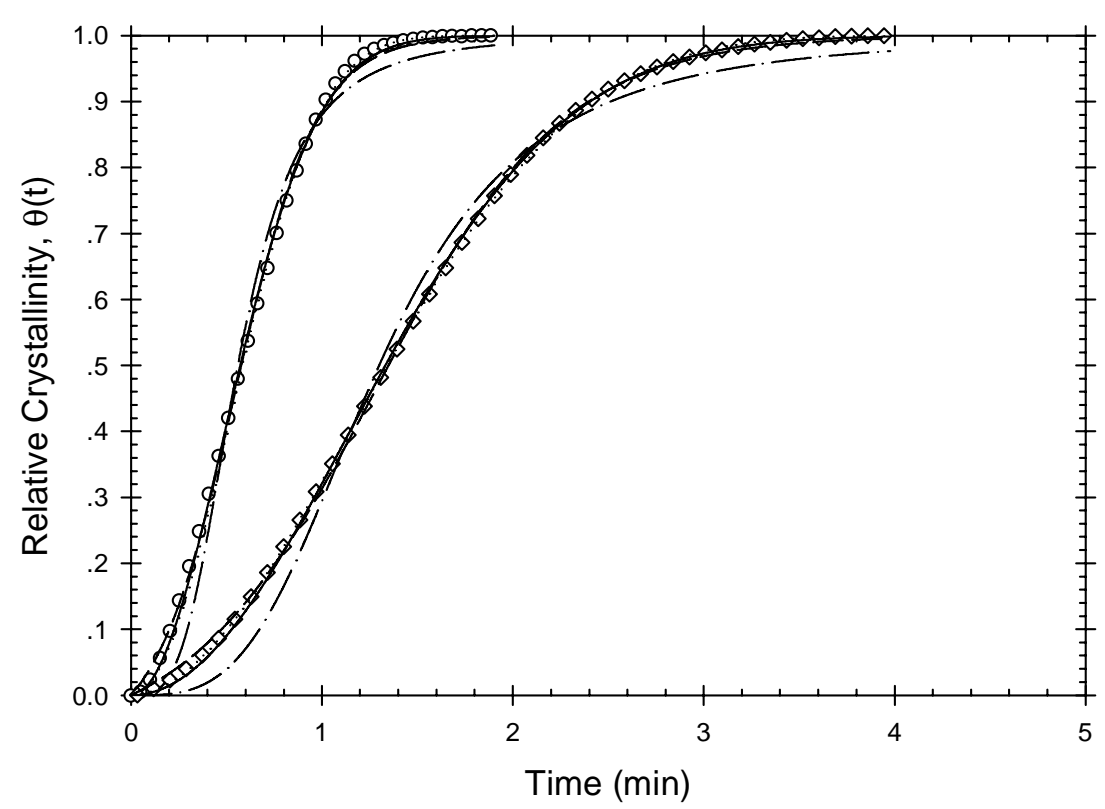

Fig. 1. Relative crystallinity as a function of time of PTT for two crystallization temperatures (i.e. $\bigcirc$ : $184{ }^{\circ} \mathrm{C}$ and $\diamond: 194{ }^{\circ} \mathrm{C}$ ). The experimental data, shown as points, were fitted to the Avrami, Tobin, and Malkin macrokinetic models, using a non-linear multivariable regression program, in which the best fits were shown as the solid, dash-dot, and dashed lines, respectively.

PET were ca. 2.6, 0.7, and $0.1 \mathrm{~min}^{-1}$, respectively. This confirmed that PBT exhibited the greatest crystallization rate, followed respectively by PTT and PET.

Observation of both the $t_{0.5}$ and $t_{0.5}^{-1}$ values suggest that the relative crystallization ability for these polyesters is in the following order: PBT $>$ PTT $>$ PET. Based on previous non-isothermal melt-crystallization kinetic analyses for these three polyesters [20], comparison of the values of the Ziabicki's kinetic crystallizability parameter (which describes the ability for a semicrystalline polymer to crystallize when it is cooled from the melt to the glassy state at a unit cooling rate and were found to be ca. 1.1, 1.5, and 1.7 for PET, PTT, and PBT, respectively) and the effective energy barrier for non-isothermal crystallization process $\Delta E$ following the differential isoconversional method of Friedman [21] (which, at a relative crystallinity of 0.5 , were found to be ca. $-49.8,-52.9$, and $-126.6 \mathrm{~kJ} \mathrm{~mol}^{-1}$ for PET, PTT, and PBT, respectively) among these three polyesters clearly support the postulation drawn above with regards to the relative crystallization ability for these polyesters.

In the case where $t_{0.5}$ data can be measured accurately over the whole temperature range in which polymers can

Table 1

Overall crystallization kinetic data for PET, PTT, and PBT based on the Avrami model

\begin{tabular}{|c|c|c|c|c|c|c|c|c|c|c|c|c|c|c|c|}
\hline \multicolumn{6}{|l|}{ PET } & \multicolumn{5}{|l|}{ PTT } & \multicolumn{5}{|l|}{ PBT } \\
\hline $\begin{array}{l}T_{\mathrm{c}} \\
\left({ }^{\circ} \mathrm{C}\right)\end{array}$ & $\begin{array}{l}t_{0.5} \\
(\mathrm{~min})\end{array}$ & $\begin{array}{l}K_{\mathrm{a}}^{*} \\
\left(\min ^{-1}\right)\end{array}$ & $n_{\mathrm{a}}$ & $\begin{array}{l}K_{\mathrm{a}} \\
\left(\min ^{-1}\right)\end{array}$ & $r^{2}$ & $\begin{array}{l}t_{0.5} \\
(\mathrm{~min})\end{array}$ & $\begin{array}{l}K_{\mathrm{a}}^{*} \\
\left(\min ^{-1}\right)\end{array}$ & $n_{\mathrm{a}}$ & $\begin{array}{l}K_{\mathrm{a}} \\
\left(\min ^{-1}\right)\end{array}$ & $r^{2}$ & $\begin{array}{l}t_{0.5} \\
(\mathrm{~min})\end{array}$ & $\begin{array}{l}K_{\mathrm{a}}^{*} \\
\left(\min ^{-1}\right)\end{array}$ & $n_{\mathrm{a}}$ & $\begin{array}{l}K_{\mathrm{a}} \\
\left(\min ^{-1}\right)\end{array}$ & $r^{2}$ \\
\hline 184 & 1.31 & 0.630 & 1.87 & 0.628 & 0.9999 & 0.58 & 1.44 & 2.03 & 1.46 & 0.9994 & 0.30 & 2.83 & 2.11 & 2.86 & 0.9996 \\
\hline 186 & 1.39 & 0.597 & 2.00 & 0.603 & 0.9995 & 0.64 & 1.26 & 1.75 & 1.27 & 0.9998 & 0.38 & 2.21 & 2.15 & 2.24 & 0.9996 \\
\hline 188 & 1.45 & 0.557 & 1.73 & 0.562 & 0.9993 & 0.72 & 1.15 & 1.98 & 1.16 & 0.9998 & 0.40 & 2.13 & 2.24 & 2.14 & 0.9997 \\
\hline 190 & 1.45 & 0.582 & 2.17 & 0.590 & 0.9999 & 0.90 & 0.934 & 2.12 & 0.940 & 0.9999 & 0.53 & 1.58 & 2.05 & 1.60 & 0.9996 \\
\hline 192 & 1.49 & 0.538 & 1.67 & 0.544 & 0.9988 & 1.05 & 0.791 & 1.96 & 0.792 & 0.9999 & 0.53 & 1.55 & 1.80 & 1.57 & 0.9994 \\
\hline 194 & 1.56 & 0.518 & 1.74 & 0.522 & 0.9994 & 1.35 & 0.621 & 2.03 & 0.626 & 0.9998 & 0.78 & 1.07 & 2.01 & 1.08 & 0.9995 \\
\hline 196 & 1.72 & 0.478 & 1.87 & 0.487 & 0.9990 & 1.57 & 0.544 & 2.29 & 0.549 & 0.9998 & 0.88 & 0.911 & 1.65 & 0.920 & 0.9993 \\
\hline 198 & 1.98 & 0.410 & 1.74 & 0.414 & 0.9988 & 2.16 & 0.386 & 2.00 & 0.387 & 0.9999 & 1.27 & 0.631 & 1.63 & 0.636 & 0.9993 \\
\hline 200 & 2.26 & 0.352 & 1.59 & 0.355 & 0.9990 & 2.97 & 0.289 & 2.40 & 0.294 & 0.9992 & 1.53 & 0.542 & 1.95 & 0.547 & 0.9995 \\
\hline 202 & 2.57 & 0.326 & 2.05 & 0.330 & 0.9997 & 3.69 & 0.228 & 2.12 & 0.228 & 0.9996 & 2.66 & 0.308 & 1.82 & 0.312 & 0.9992 \\
\hline 204 & 2.84 & 0.288 & 1.83 & 0.302 & 0.9967 & 4.95 & 0.172 & 2.27 & 0.172 & 0.9996 & 3.65 & 0.219 & 1.63 & 0.219 & 0.9970 \\
\hline 205 & 2.97 & 0.275 & 1.82 & 0.276 & 0.9997 & 5.93 & 0.145 & 2.39 & 0.147 & 0.9993 & - & - & - & - & - \\
\hline 206 & 2.98 & 0.276 & 1.86 & 0.282 & 0.9972 & 6.61 & 0.129 & 2.24 & 0.129 & 0.9998 & 4.76 & 0.169 & 1.66 & 0.170 & 0.9912 \\
\hline 207 & 3.29 & 0.249 & 1.84 & 0.249 & 0.9998 & - & - & - & - & - & - & - & - & - & - \\
\hline 208 & 3.99 & 0.207 & 1.91 & 0.210 & 0.9980 & 7.60 & 0.113 & 2.39 & 0.114 & 0.9989 & 7.46 & 0.110 & 1.85 & 0.113 & 0.9971 \\
\hline 215 & 4.71 & 0.176 & 1.97 & 0.173 & 0.9991 & - & - & - & - & - & - & - & - & - & - \\
\hline 220 & 10.2 & 0.082 & 2.05 & 0.082 & 0.9992 & - & - & - & - & - & - & - & - & - & - \\
\hline
\end{tabular}




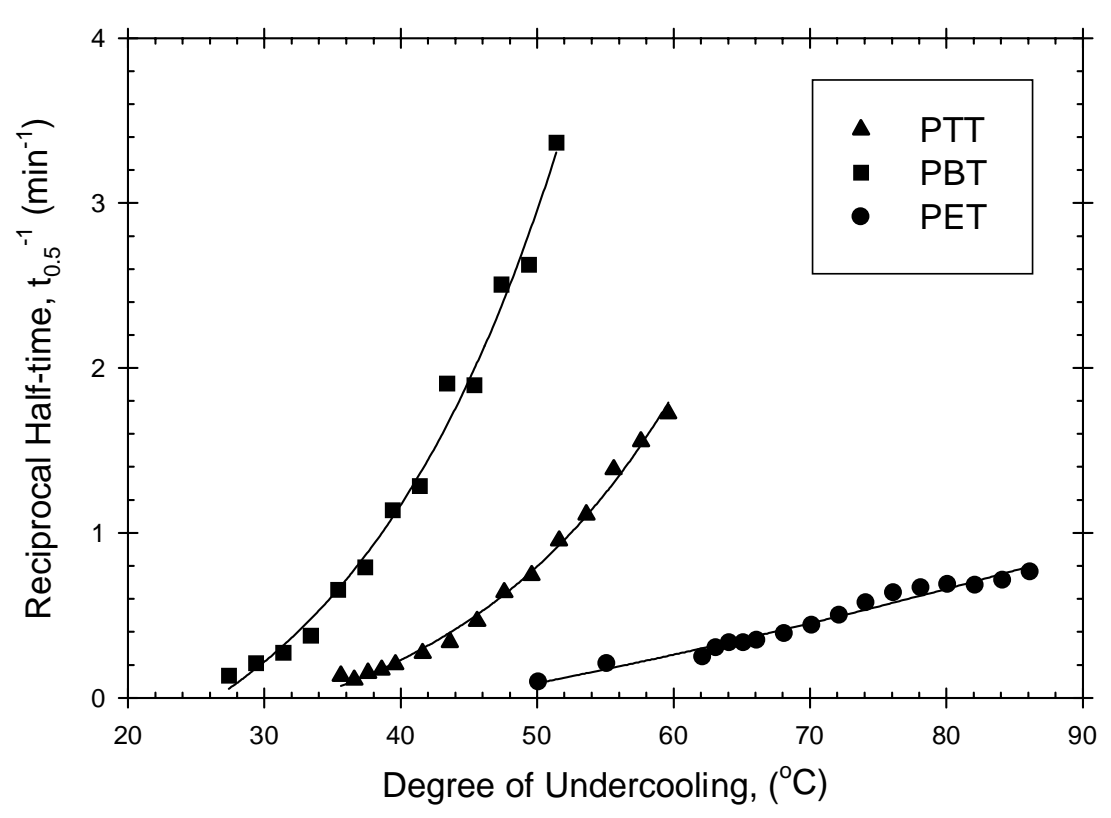

Fig. 2. Reciprocal half-time of crystallization $t_{0.5}^{-1}$ as a function of degree of undercooling for PET, PTT, and PBT.

crystallize (i.e. $T_{\mathrm{g}}<T_{\mathrm{c}}<T_{\mathrm{m}}^{0}$ ), the plot of the $t_{0.5}^{-1}$ versus either $T_{\mathrm{c}}$ or $\Delta T$ is expected to exhibit the typical bell-shaped curve, which is characterized by the nucleation-controlled character at "high" $T_{\mathrm{c}}$ or "low" $\Delta T$ values and the diffusion-controlled one at "low" $T_{\mathrm{c}}$ or "high" $\Delta T$ values. Such behavior can be theoretically described based on the Lauritzen-Hoffman secondary nucleation concept $[22,23]$. From the results shown in Fig. 2, it is apparent that, within the $T_{\mathrm{c}}$ range studied, these polyesters crystallized within the nucleation-controlled region.

Though it is not visually observed in the $t_{0.5}^{-1}$ versus $\Delta T$ data for PTT and PBT, a "breaking" behavior in the data presented for PET at a $\Delta T$ just above ca. $60^{\circ} \mathrm{C}$ or a $T_{\mathrm{c}}$ just below ca. $210^{\circ} \mathrm{C}$ is obvious (see Fig. 2). Vyazovkin and Sbirrazzuoli [24] used the integral isoconversional method of Vyazovkin [25,26] to obtain the effective energy barrier for isothermal crystallization of PET and reported that the temperature dependence of the $\Delta E$ exhibited a breakpoint at an average temperature of ca. $205^{\circ} \mathrm{C}$. Lu and Hay [27] applied the Lauritzen-Hoffman concept $[22,23]$ to the isothermal bulk crystallization data of PET and reported a break in the slope of the respective plot at a $T_{\mathrm{c}}$ of ca. $217^{\circ} \mathrm{C}$, in which they attributed to the change in the crystallization regimes from I to II. Based on these observations, the "breaking" behavior observed here should correspond to the change in the crystallization regimes.

\subsection{Isothermal crystallization kinetics based on the Avrami analysis}

The analysis of kinetic data based on the Avrami model can be done by fitting the $\theta(t)$ function obtained for each crystallization temperature to Eq. (1). The Avrami exponent $n_{\mathrm{a}}$ and the Avrami rate constant $K_{\mathrm{a}}$, provided by the program, are summarized in Table 1 . The exponent $n_{\mathrm{a}}$ for primary crystallization process was found to range from 1.64 to 2.05 for PET, 1.75 to 2.39 for PTT, and 1.63 to 2.24 for PBT, respectively. This may correspond to a two dimensional growth with a combination of thermal and athermal nucleation (resulting in the fractional $n_{\mathrm{a}}$ values observed) [28]. Intuitively, the temperature dependence of the exponent $n_{\mathrm{a}}$, within the nucleation-controlled region, should be such that $n_{\mathrm{a}}$ decreases with decreasing crystallization temperature. This may be explained based on the fact that the number of athermal nuclei increases tremendously as the temperature decreases $[18,29]$. In other words, as the crystallization temperature decreases, the number of athermal nuclei that become stable at that temperature also increased, resulting in the nucleation mechanism becoming more instantaneous in time and causing the Avrami exponent $n_{\mathrm{a}}$ to decrease.

From the kinetic data shown in Table $1, K_{\mathrm{a}}$ was very sensitive to changes in the $T_{\mathrm{c}}$, in that it increased with decreasing $T_{\mathrm{c}}$ (or with increasing $\Delta T$ ), similar to the case of $t_{0.5}^{-1}$ previously shown. Indeed, $K_{\mathrm{a}}$ values can be calculated directly from the $t_{0.5}^{-1}$ values (i.e. $\left.K_{\mathrm{a}}^{*}=(\ln 2)^{1 / n_{\mathrm{a}}}\left(t_{0.5}^{-1}\right)\right)$, in which the calculated rate constant values $K_{\mathrm{a}}^{*}$ are also listed for comparison in Table 1. Obviously, there is good agreement between the rate constant obtained from the fitting of the experimental data $K_{\mathrm{a}}$ and that obtained from the calculation $K_{\mathrm{a}}^{*}$, with the calculated value being ca. $0.73 \%$ less than the experimental values on average for PTT.

\subsection{Isothermal crystallization kinetics based on the Tobin analysis}

The analysis based on the Tobin model can be performed by fitting the $\theta(t)$ function obtained for each crystallization temperature to Eq. (3). Table 2 summarizes the Tobin kinetic 
Table 2

Overall crystallization kinetic data for PET, PTT, and PBT based on the Tobin model

\begin{tabular}{|c|c|c|c|c|c|c|c|c|c|c|c|c|c|c|c|}
\hline \multicolumn{6}{|l|}{ PET } & \multicolumn{5}{|l|}{ PTT } & \multicolumn{5}{|l|}{ PBT } \\
\hline $\begin{array}{l}T_{\mathrm{c}} \\
\left({ }^{\circ} \mathrm{C}\right)\end{array}$ & $\begin{array}{l}t_{0.5} \\
(\mathrm{~min})\end{array}$ & $n_{\mathrm{t}}$ & $\begin{array}{l}K_{\mathrm{t}} \\
\left(\min ^{-1}\right)\end{array}$ & $r^{2}$ & $\begin{array}{l}K_{\mathrm{t}}^{*} \\
\left(\min ^{-1}\right)\end{array}$ & $\begin{array}{l}t_{0.5} \\
(\mathrm{~min})\end{array}$ & $n_{\mathrm{t}}$ & $\begin{array}{l}K_{\mathrm{t}} \\
\left(\min ^{-1}\right)\end{array}$ & $r^{2}$ & $\begin{array}{l}K_{\mathrm{t}}^{*} \\
\left(\min ^{-1}\right)\end{array}$ & $\begin{array}{l}t_{0.5} \\
(\mathrm{~min})\end{array}$ & $n_{\mathrm{t}}$ & $\begin{array}{l}K_{\mathrm{t}} \\
\left(\min ^{-1}\right)\end{array}$ & $r^{2}$ & $\begin{array}{l}K_{\mathrm{t}}^{*} \\
\left(\min ^{-1}\right)\end{array}$ \\
\hline 184 & 1.13 & 2.81 & 0.914 & 0.9913 & 0.885 & 0.58 & 3.43 & 1.79 & 0.9919 & 1.72 & 0.30 & 3.66 & 3.48 & 0.9939 & 3.37 \\
\hline 186 & 1.39 & 3.47 & 0.737 & 0.9927 & 0.717 & 0.64 & 3.06 & 1.60 & 0.9943 & 1.56 & 0.38 & 3.70 & 2.70 & 0.9938 & 2.63 \\
\hline 188 & 1.45 & 2.83 & 0.714 & 0.9901 & 0.688 & 0.72 & 3.35 & 1.42 & 0.9937 & 1.39 & 0.40 & 3.85 & 2.58 & 0.9942 & 2.51 \\
\hline 190 & 1.45 & 3.41 & 0.717 & 0.9922 & 0.689 & 0.90 & 3.57 & 1.01 & 0.9940 & 1.11 & 0.53 & 3.64 & 1.95 & 0.9935 & 1.89 \\
\hline 192 & 1.49 & 2.69 & 0.697 & 0.9885 & 0.670 & 1.05 & 3.18 & 0.982 & 0.9946 & 0.953 & 0.53 & 3.28 & 1.94 & 0.9918 & 1.91 \\
\hline 194 & 1.56 & 2.81 & 0.662 & 0.9907 & 0.639 & 1.35 & 3.34 & 0.770 & 0.9936 & 0.743 & 0.78 & 3.45 & 1.32 & 0.9927 & 1.28 \\
\hline 196 & 1.72 & 3.07 & 0.608 & 0.9895 & 0.582 & 1.57 & 3.62 & 0.661 & 0.9941 & 0.639 & 0.88 & 2.97 & 1.16 & 0.9904 & 1.14 \\
\hline 198 & 1.98 & 2.79 & 0.528 & 0.9888 & 0.506 & 2.16 & 3.30 & 0.478 & 0.9958 & 0.464 & 1.27 & 2.90 & 0.808 & 0.9899 & 0.790 \\
\hline 200 & 2.26 & 2.55 & 0.460 & 0.9889 & 0.443 & 2.97 & 3.65 & 0.352 & 0.9915 & 0.337 & 1.53 & 3.35 & 0.674 & 0.9921 & 0.654 \\
\hline 202 & 2.57 & 3.34 & 0.405 & 0.9926 & 0.390 & 3.69 & 3.16 & 0.281 & 0.9929 & 0.271 & 2.66 & 3.04 & 0.389 & 0.9905 & 0.377 \\
\hline 204 & 2.84 & 2.82 & 0.386 & 0.9846 & 0.352 & 4.95 & 3.78 & 0.209 & 0.9955 & 0.202 & 3.65 & 2.46 & 0.283 & 0.9863 & 0.274 \\
\hline 205 & 2.97 & 2.92 & 0.346 & 0.9958 & 0.337 & 5.93 & 3.68 & 0.176 & 0.9922 & 0.169 & - & - & - & - & - \\
\hline 206 & 2.98 & 2.82 & 0.355 & 0.9856 & 0.336 & 6.61 & 3.51 & 0.157 & 0.9948 & 0.151 & 4.76 & 2.56 & 0.216 & 0.9925 & 0.210 \\
\hline 207 & 3.29 & 2.92 & 0.313 & 0.9941 & 0.304 & - & - & - & - & - & - & - & - & - & - \\
\hline 208 & 3.99 & 2.81 & 0.262 & 0.9881 & 0.251 & 7.60 & 3.65 & 0.136 & 0.9916 & 0.132 & 7.46 & 2.78 & 0.142 & 0.9899 & 0.134 \\
\hline 215 & 4.71 & 2.87 & 0.218 & 0.9927 & 0.212 & - & - & - & - & - & - & - & - & - & - \\
\hline 220 & 10.2 & 3.12 & 0.099 & 0.9921 & 0.098 & - & - & - & - & - & - & - & - & - & - \\
\hline
\end{tabular}

parameters $n_{\mathrm{t}}$ and $K_{\mathrm{t}}$, as well as the $r^{2}$ parameter. The Tobin exponent $n_{\mathrm{t}}$ for primary crystallization was found to range from 2.55 to 3.47 for PET, 3.06 to 3.78 for PTT, and 2.46 to 3.85 for PBT. By comparison, it is apparent that, at an arbitrary crystallization temperature, the Avrami exponent $n_{\mathrm{a}}$ is consistently lower in value than the Tobin exponent $n_{\mathrm{t}}$. By taking the average value of the difference between the two values, we are able to conclude, based on our experimental observation, that $n_{\mathrm{t}} \approx n_{\mathrm{a}}+1.3$, which is in general accordance with previous observations $[18,29]$.

As may be seen from Table 2, the Tobin rate constant $K_{\mathrm{t}}$ clearly exhibits a similar trend to that of the Avrami rate constant $K_{\mathrm{a}}$ in that it is greater in its value at low crystallization temperatures than that at high temperatures. According to Eq. (3), the Tobin rate constant can also be calculated from the reciprocal half-time value $t_{0.5}^{-1}$ (i.e. $K_{\mathrm{t}}^{*}=t_{0.5}^{-1}$ ). The calculated values $K_{\mathrm{t}}^{*}$ are also listed in Table 2. The discrepancy between the average value of rate constant obtained from the fitting of the experimental data $K_{\mathrm{t}}$ and that obtained from the calculation $K_{\mathrm{t}}^{*}$ of $1.89 \%$ for PTT was found, as opposed to around $0.73 \%$ difference in $K_{\mathrm{a}}$ and $K_{\mathrm{t}}^{*}$ values for PTT. The analysis for PET and PBT also showed similar trends. This suggests that the experimental data for these polyesters can be better described by the Avrami model better than by the Tobin one. This is also reflected by the fact that the $r^{2}$ values listed in Table 1 are much greater than those listed in Table 2, indicating the much better fitting of the data to the Avrami model.

\subsection{Isothermal crystallization kinetics based on the Malkin analysis}

The analysis based on the Malkin model can be carried out by fitting the $\theta(t)$ function obtained for each crystallization temperature to Eq. (4). The kinetic parameters specific to the Malkin model, $C_{0}$ and $C_{1}$, as well as $r^{2}$ parameter, are listed in Table 3 . The $C_{0}$ parameter was found to range from 4.55 to 25.74 for PET, 7.01 to 28.01 for PTT and 4.56 to 17.39 for PBT.

Unlike the Avrami and the Tobin models, there is no direct analytical procedure for the determination of the Malkin kinetic parameters. Since, fundamentally, the Malkin exponent $C_{0}$ is related directly to the Avrami exponent $n_{\mathrm{a}}$ according to the following expression [17]:

$C_{0}=4^{n_{\mathrm{a}}}-4$,

it should exhibit a similar temperature dependence to that of Avrami exponent $n_{\mathrm{a}}$. According to the data presented in Table 3, the Malkin rate constant $C_{1}$ also exhibited a temperature dependence in a similar fashion as the crystallization rate constants characteristic of both the Avrami and Tobin models. This is not surprising since the Malkin rate constant $C_{1}$ relates to the Avrami kinetic parameters (i.e. $n_{\mathrm{a}}$ and $k_{\mathrm{a}}$ ) according to the following expression [17]:

$C_{1}=\frac{\ln \left(4^{n_{\mathrm{a}}}-2\right) K_{\mathrm{a}}}{(\ln 2)^{n_{\mathrm{a}}}}$.

The estimated Malkin kinetic parameters are also listed in Table 4 , in which they are denoted $C_{0}^{*}$ and $C_{1}^{*}$, respectively. The estimated rate constant $C_{1}^{*}$ was found to be in good agreement with that obtained from the direct fitting method for $C_{1}$. Like the other two rate constants, the Malkin rate constant $C_{1}$ can also be calculated directly from the reciprocal half-time $t_{0.5}^{-1}$ (i.e. $C_{1}=\ln \left(4^{n_{\mathrm{a}}}-2\right)\left(t_{0.5}^{-1}\right)$ ). Although not listed in Table 3, the $C_{1}$ values calculated from $t_{0.5}^{-1}$ values were found to be almost identical to the estimated Malkin values, $C_{1}^{*}$, for the crystallization rate constants. 
Table 3

Overall crystallization kinetic data for PET, PTT, and PBT based on the Malkin model

\begin{tabular}{|c|c|c|c|c|c|c|c|c|c|c|c|c|c|c|c|c|c|c|}
\hline \multicolumn{7}{|l|}{ PET } & \multicolumn{6}{|l|}{ PTT } & \multicolumn{6}{|l|}{ PBT } \\
\hline $\begin{array}{l}T_{\mathrm{c}} \\
\left({ }^{\circ} \mathrm{C}\right)\end{array}$ & $\begin{array}{l}t_{0.5} \\
(\mathrm{~min})\end{array}$ & $C_{0}$ & $\begin{array}{l}C_{1} \\
\left(\min ^{-1}\right)\end{array}$ & $r^{2}$ & $C_{0}^{*}$ & $\begin{array}{l}C_{1}^{*} \\
\left(\min ^{-1}\right)\end{array}$ & $\begin{array}{l}t_{0.5} \\
(\mathrm{~min})\end{array}$ & $C_{0}$ & $\begin{array}{l}C_{1} \\
\left(\min ^{-1}\right)\end{array}$ & $r^{2}$ & $C_{1}^{*}$ & $\begin{array}{l}C_{2}^{*} \\
\left(\min ^{-1}\right)\end{array}$ & $\begin{array}{l}t_{0.5} \\
(\mathrm{~min})\end{array}$ & $C_{0}$ & $\begin{array}{l}C_{1} \\
\left(\min ^{-1}\right)\end{array}$ & $r^{2}$ & $C_{1}^{*}$ & $\begin{array}{l}C_{2}^{*} \\
\left(\min ^{-1}\right)\end{array}$ \\
\hline 184 & 1.13 & 5.95 & 1.82 & 0.9997 & 6.27 & 1.88 & 0.58 & 13.3 & 4.72 & 0.9994 & 12.7 & 4.69 & 0.297 & 13.3 & 9.25 & 0.9998 & 14.6 & 9.56 \\
\hline 186 & 1.39 & 10.7 & 1.84 & 0.9997 & 12.0 & 1.91 & 0.64 & 7.01 & 3.41 & 0.9997 & 7.30 & 3.50 & 0.381 & 14.56 & 7.42 & 0.9998 & 15.7 & 7.62 \\
\hline 188 & 1.45 & 6.49 & 1.47 & 0.9995 & 7.00 & 1.53 & 0.72 & 12.0 & 3.63 & 0.9995 & 11.6 & 3.62 & 0.399 & 17.39 & 7.48 & 0.9998 & 18.3 & 7.60 \\
\hline 190 & 1.45 & 17.5 & 2.05 & 0.9994 & 16.3 & 2.70 & 0.90 & 17.4 & 3.28 & 0.9994 & 14.9 & 3.16 & 0.528 & 12.22 & 5.06 & 0.9998 & 13.2 & 5.21 \\
\hline 192 & 1.49 & 5.71 & 1.37 & 0.9990 & 6.13 & 1.42 & 1.05 & 11.5 & 2.46 & 0.9997 & 11.1 & 2.46 & 0.525 & 6.82 & 4.18 & 0.9997 & 8.13 & 4.45 \\
\hline 194 & 1.56 & 7.20 & 1.41 & 0.9993 & 7.16 & 1.43 & 1.35 & 13.7 & 2.04 & 0.9997 & 12.7 & 2.02 & 0.779 & 10.93 & 3.31 & 0.9997 & 12.2 & 3.44 \\
\hline 196 & 1.72 & 9.02 & 1.41 & 0.9992 & 9.36 & 1.44 & 1.57 & 23.8 & 2.07 & 0.9995 & 19.9 & 1.99 & 0.879 & 4.86 & 2.20 & 0.9997 & 5.85 & 2.37 \\
\hline 198 & 1.98 & 7.10 & 1.12 & 0.9989 & 7.16 & 1.13 & 2.16 & 11.7 & 1.21 & 0.9995 & 12.0 & 1.23 & 1.27 & 4.56 & 1.50 & 0.9997 & 5.58 & 1.61 \\
\hline 200 & 2.26 & 4.55 & 0.870 & 0.9993 & 5.06 & 0.872 & 2.97 & 28.0 & 1.15 & 0.9998 & 23.9 & 1.11 & 1.53 & 9.67 & 1.62 & 0.9997 & 10.9 & 1.69 \\
\hline 202 & 2.57 & 13.5 & 1.07 & 0.9997 & 13.1 & 1.07 & 3.69 & 16.3 & 0.780 & 0.9989 & 14.9 & 0.766 & 2.66 & 7.28 & 0.846 & 0.9997 & 8.47 & 0.896 \\
\hline 204 & 2.84 & 14.0 & 0.960 & 0.9973 & 8.64 & 0.873 & 4.95 & 22.2 & 0.644 & 0.9996 & 19.3 & 0.620 & 3.65 & 5.93 & 0.558 & 0.9971 & 5.58 & 0.556 \\
\hline 205 & 2.97 & 8.25 & 0.780 & 0.9994 & 8.47 & 0.793 & 5.93 & 27.7 & 0.575 & 0.9986 & 23.5 & 0.554 & - & - & - & - & - & - \\
\hline 206 & 2.98 & 9.61 & 0.832 & 0.9975 & 9.18 & 0.829 & 6.61 & 19.4 & 0.463 & 0.9994 & 18.3 & 0.458 & 4.76 & 5.57 & 0.425 & 0.9986 & 5.99 & 0.440 \\
\hline 207 & 3.29 & 8.96 & 0.721 & 0.9995 & 8.82 & 0.725 & - & - & - & - & - & - & - & - & - & - & - & - \\
\hline 208 & 3.99 & 11.3 & 0.643 & 0.9977 & 10.1 & 0.634 & 7.60 & 26.5 & 0.444 & 0.9991 & 23.5 & 0.432 & 7.46 & 8.70 & 0.321 & 0.9980 & 9.00 & 0.331 \\
\hline 215 & 4.71 & 11.6 & 0.539 & 0.9981 & 11.3 & 0.541 & - & - & - & - & - & - & - & - & - & - & - & - \\
\hline 220 & 10.2 & 13.5 & 0.266 & 0.9910 & 13.1 & 0.265 & - & - & - & - & - & - & - & - & - & - & - & - \\
\hline
\end{tabular}


Table 4

Fitting parameters for the best possible fits of the respective rate parameters of PET, PTT, and PBT according to Eq. (9)

\begin{tabular}{|c|c|c|c|c|c|c|c|c|c|c|c|c|c|c|}
\hline \multicolumn{5}{|l|}{ PET } & \multicolumn{5}{|l|}{ PTT } & \multicolumn{5}{|l|}{ PBT } \\
\hline$C(\mathrm{~K})$ & $\psi_{0}$ & $\begin{array}{l}A \\
\left(\mathrm{cal} \mathrm{mol}^{-1}\right)\end{array}$ & $B\left(\mathrm{~K}^{2}\right)$ & $r^{2}$ & $C(\mathrm{~K})$ & $\psi_{0}$ & $\begin{array}{l}A \\
\left(\mathrm{cal} \mathrm{mol}{ }^{-1}\right)\end{array}$ & $B\left(\mathrm{~K}^{2}\right)$ & $r^{2}$ & $C(\mathrm{~K})$ & $\psi_{0}$ & $\begin{array}{l}A \\
\left(\mathrm{cal} \mathrm{mol}^{-1}\right)\end{array}$ & $B\left(\mathrm{~K}^{2}\right)$ & $r^{2}$ \\
\hline \multicolumn{15}{|c|}{$t_{0.5}^{-1}\left(\min ^{-1}\right)$} \\
\hline 30 & $1.29 \times 10^{8}$ & 2687 & $3.25 \times 10^{5}$ & 0.9626 & 30 & $1.11 \times 10^{7}$ & 2684 & $1.97 \times 10^{5}$ & 0.9964 & 30 & $4.73 \times 10^{4}$ & 1500 & $1.20 \times 10^{5}$ & 0.9722 \\
\hline 50 & $1.23 \times 10^{8}$ & 3215 & $3.07 \times 10^{5}$ & 0.9566 & 50 & $5.75 \times 10^{7}$ & 3544 & $2.02 \times 10^{5}$ & 0.9964 & 50 & $2.55 \times 10^{4}$ & 1500 & $1.15 \times 10^{5}$ & 0.9725 \\
\hline \multicolumn{15}{|c|}{$K_{\mathrm{a}}\left(\min ^{-1}\right)$} \\
\hline 30 & $6.33 \times 10^{7}$ & 2590 & $3.19 \times 10^{5}$ & 0.9341 & 30 & $2.37 \times 10^{6}$ & 2348 & $1.88 \times 10^{5}$ & 0.9964 & 30 & $4.70 \times 10^{4}$ & 1500 & $1.23 \times 10^{5}$ & 0.9776 \\
\hline 50 & $1.48 \times 10^{5}$ & 1866 & $2.28 \times 10^{5}$ & 0.9017 & 50 & $2.80 \times 10^{4}$ & 1398 & $1.57 \times 10^{5}$ & 0.9958 & 50 & $2.53 \times 10^{4}$ & 1500 & $1.19 \times 10^{5}$ & 0.9775 \\
\hline \multicolumn{15}{|c|}{$K_{\mathrm{t}}\left(\min ^{-1}\right)$} \\
\hline 30 & $9.09 \times 10^{7}$ & 2640 & $3.18 \times 10^{5}$ & 0.9578 & 30 & $1.22 \times 10^{5}$ & 1500 & $1.71 \times 10^{5}$ & 0.9831 & 30 & $5.07 \times 10^{4}$ & 1500 & $1.21 \times 10^{5}$ & 0.9737 \\
\hline 50 & $8.98 \times 10^{7}$ & 3164 & $3.01 \times 10^{5}$ & 0.9512 & 50 & $5.75 \times 10^{4}$ & 1500 & $1.64 \times 10^{5}$ & 0.9832 & 50 & $2.73 \times 10^{4}$ & 1500 & $1.16 \times 10^{5}$ & 0.9740 \\
\hline \multicolumn{15}{|c|}{$C_{1}\left(\min ^{-1}\right)$} \\
\hline 30 & $1.52 \times 10^{6}$ & 1647 & $2.72 \times 10^{5}$ & 0.8059 & 30 & $1.50 \times 10^{5}$ & 1500 & $1.53 \times 10^{5}$ & 0.9276 & 30 & $7.78 \times 10^{5}$ & 1708 & $1.45 \times 10^{5}$ & 0.9543 \\
\hline 50 & $6.57 \times 10^{6}$ & 2269 & $2.80 \times 10^{5}$ & 0.8062 & 50 & $7.09 \times 10^{4}$ & 1500 & $1.46 \times 10^{5}$ & 0.9277 & 50 & $3.18 \times 10^{5}$ & 1648 & $1.40 \times 10^{5}$ & 0.9568 \\
\hline
\end{tabular}


4.5. Qualitative comparison among the three macrokinetic models

The quality of each macrokinetic equation in describing the experimental data $\theta(t)$ is quantitatively represented by not only the $r^{2}$ parameter obtained for the best fit of the data, but also the quality of the prediction in comparison with the experimental data such as those shown in Fig. 1. From the comparison of the model predictions of the experimental data (shown in Figure as solid, dash-dot, and dashed lines for predictions according to the Avrami, Tobin, and Malkin models, respectively) and the comparison of the values of the $r^{2}$ parameter summarized in Tables 1-3 it is clear that the Avrami and Malkin models provide very good correlation of the experimental data, while the Tobin model was not satisfactory in describing the experimental data.

\subsection{Further discussion on the temperature dependence of the kinetic paramters}

Fig. 3 illustrates the variation of all of the kinetic exponents of time (i.e. $n_{\mathrm{a}}, n_{\mathrm{t}}$, and $C_{0}$ ) as a function of $T_{\mathrm{c}}$ (only shown for PTT). The values of $n_{\mathrm{a}}$ and $n_{\mathrm{t}}$ change a little with, while $C_{0}$ was a bit more sensitive to, changes in the $T_{\mathrm{c}}$. The kinetic exponents of time for PET and PBT also exhibited similar temperature dependency. Fig. 4 exhibits the variation of all of the bulk crystallization rate parameters (i.e. $t_{0.5}^{-1}, K_{\mathrm{a}}, K_{\mathrm{t}}$, and $C_{1}$ ) as a function of $T_{\mathrm{c}}$ (only shown for PTT). Apparently, all of the bulk crystallization rate parameters exhibited a similar temperature dependence. Since the units of these rate parameters were identical (i.e. $\min ^{-1}$ ) and all of the crystallization rate parameters relate, in one way or another, to the $t_{0.5}^{-1}$, this similarity is not unexpected.
It is generally accepted $[18,29]$ that the bulk crystallization rate parameters (e.g. $t_{0.5}^{-1}, K_{\mathrm{a}}, K_{\mathrm{t}}$, and $C_{1}$ ) relate, in one way or another, to the primary nucleation rate $I$ and/or the subsequent crystal growth rate $G$ : the temperature dependence of the bulk rate parameters can accordingly be quantified and described. Even though the temperature dependence of the parameters $I$ and $G$ are known to have a different temperature dependence $[22,23]$, the bulk crystallization rate parameters have often been taken to have a similar temperature dependence to that of the subsequent crystal growth rate $G$ (written in the context of the original Lauritzen-Hoffman secondary nucleation theory (LH theory) $[22,23]$ ), which can be expressed as

$\psi\left(T_{\mathrm{c}}\right)=\psi_{0} \exp \left(-\frac{A}{R\left(T_{\mathrm{c}}-\left(T_{\mathrm{g}}-C\right)\right)}-\frac{B}{\left.T_{\mathrm{c}}(\Delta T) f\right)}\right)$,

where $\psi\left(T_{\mathrm{c}}\right)$ and $\psi_{0}$ are the respective crystallization rate parameters (i.e. $t_{0.5}^{-1}, K_{\mathrm{a}}, K_{\mathrm{t}}$, and $C_{1}$ ) and the respective pre-exponential parameters (i.e. $\left(t_{0.5}^{-1}\right)_{0}, K_{\mathrm{a}, 0}, K_{\mathrm{t}, 0}$, and $\left.C_{1,0}\right)$, respectively. $A$ is a parameter relating to the activation energy which characterizes molecular diffusion across the interfacial boundary between melt and crystals, while $B$ is a parameter relating to the activation energy for the formation of the secondary nuclei. $T_{\mathrm{g}}$ is the respective glass-transition temperature (i.e. $T_{\mathrm{g}} \approx 78^{\circ} \mathrm{C}$ for PET, $44^{\circ} \mathrm{C}$ for PTT, and $35^{\circ} \mathrm{C}$ for PBT, respectively), $T_{\mathrm{g}}-\mathrm{C}$ is the temperature where the cessation of long range molecular motion is expected and is often taken to be either ca. 30 or $50 \mathrm{~K}$ below the glass-transition temperature, $R$ is the universal gas constant, and $f$ is the factor used to correct for the temperature dependence of the heat of fusion (i.e. $f=2 T_{\mathrm{c}} /\left(T_{\mathrm{c}}+T_{\mathrm{m}}^{0}\right)$ ).

The temperature-dependent crystallization rate function $\psi\left(T_{\mathrm{c}}\right)$ can be determined by fitting each respective

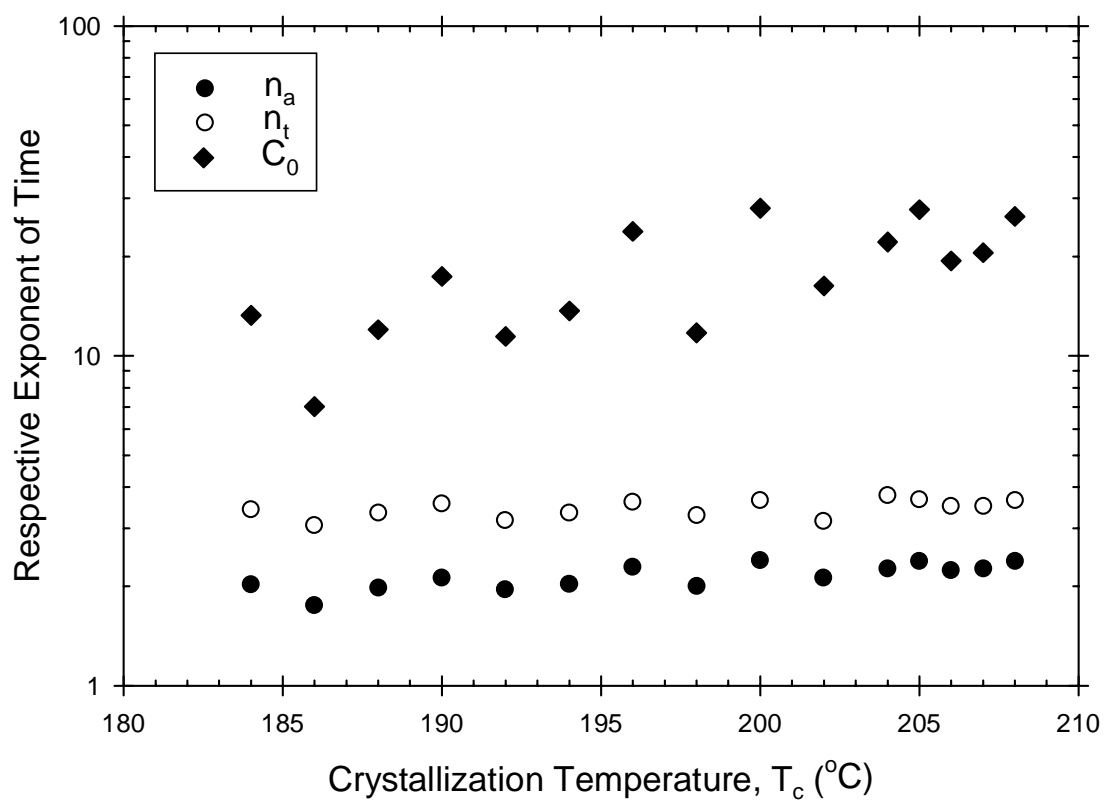

Fig. 3. Respective exponent of time specific to the Avrami, Tobin, and Malkin macrokinetic models as a function of crystallization temperature. 


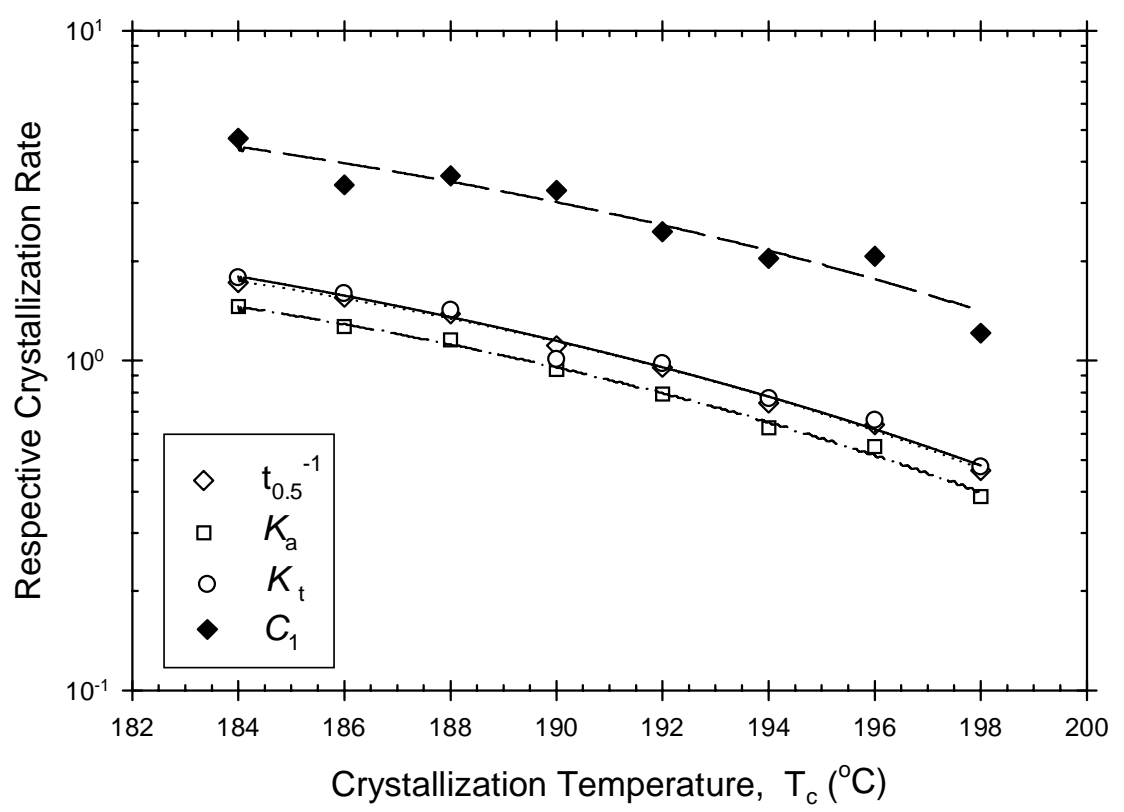

Fig. 4. Respective kinetic rate of crystallization specific to the Avrami, Tobin, and Malkin macrokinetic models as a function of crystallization temperature. The experimental data, shown as various geometrical points, were fitted to Eq. (7), and the best fits are shown as various lines.

crystallization rate parameter (i.e. $t_{0.5}^{-1}, K_{\mathrm{a}}, K_{\mathrm{t}}$, and $C_{1}$ ) collected at various $T_{\mathrm{c}}$ 's to Eq. (7). In order to obtain the best possible fits for the rate parameters with Eq. (7), the value of the parameter $C$ was chosen to be either 30 or $50 \mathrm{~K}$, while those of $T_{\mathrm{g}}$ and $T_{\mathrm{m}}^{0}$ were fixed as previously noted. In so doing, the only unknown parameters which are provided by the program along with the best fits are $\psi_{0}, A$ and $B$. Plots of the crystallization rate parameter of interest (i.e. $t_{0.5}^{-1}, K_{\mathrm{a}}$, $K_{\mathrm{t}}$, and $\left.C_{1}\right)$ and its corresponding best fit are illustrated in Fig. 4. The values of the fitting parameters are summarized in Table 4. Examination of the values of the $r^{2}$ parameter listed in Table 4 suggests that the goodness of the fits of these parameters according to Eq. (7) was very satisfactory. Specifically, it can be concluded that the quality of the fits, when using $C=30 \mathrm{~K}$, was, in general, better than those, when using $C=50 \mathrm{~K}$ for PET and PTT. On the other hand, use of $C=50 \mathrm{~K}$ was better in the case of PBT.

\subsection{Crystal modification and crystallinity of PTT}

In order to observe the crystal structure and the resulting apparent degree of crystallinity of PTT samples crystallized at different isothermal temperatures, the WAXD technique was used. Fig. 5 shows WAXD patterns of PTT samples

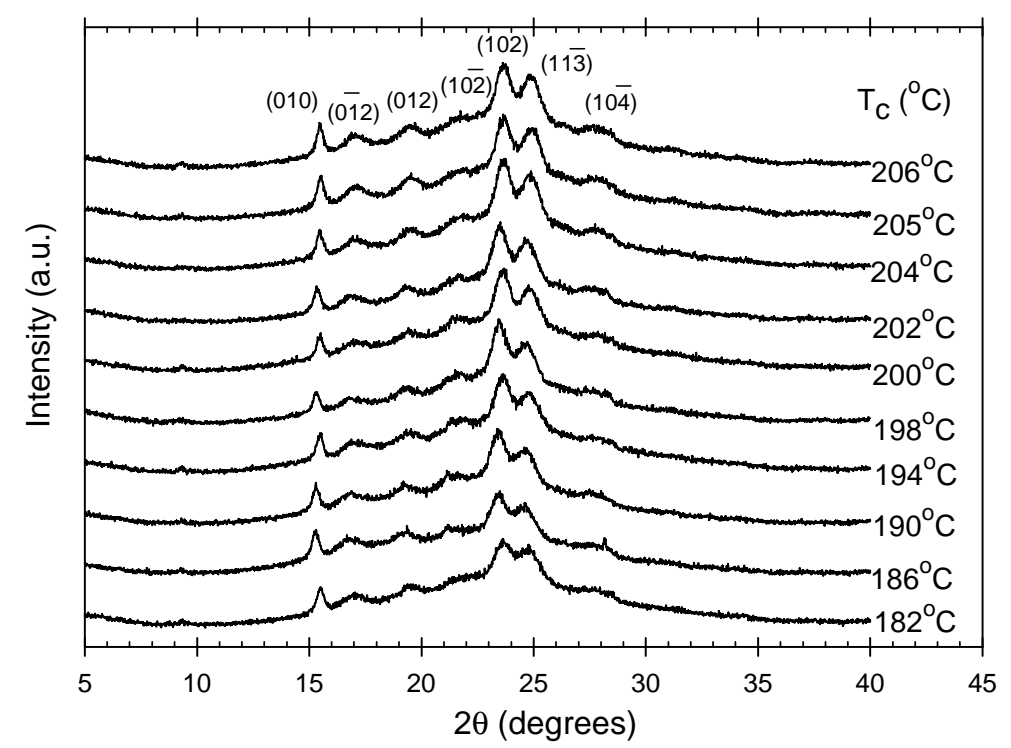

Fig. 5. Wide-angle X-ray diffractograms for PTT samples isothermally crystallized from the melt state at different crystallization temperatures. 
crystallized at isothermal temperatures ranging from 182 to $206^{\circ} \mathrm{C}$ (each sample was prepared in a DSC cell by quenching to $30^{\circ} \mathrm{C}$, without subsequent melting, after complete crystallization at each respective temperature). Obviously, each samples exhibited seven characteristics peaks at the scattering angles $2 \theta$ of ca. 15.3, 16.8, 19.4, 21.8, 23.6, 24.6, and $27.3^{\circ}$, corresponding to the reflection planes of $(010)$, $\left(\begin{array}{lll}0 & \overline{1} & 2\end{array}\right),\left(\begin{array}{lll}0 & 1 & 2\end{array}\right),\left(\begin{array}{lll}1 & 0 & \overline{2}\end{array}\right),\left(\begin{array}{lll}1 & 0 & 2\end{array}\right),\left(\begin{array}{lll}1 & \overline{1} & 3\end{array}\right)$ and $\left(\begin{array}{lll}1 & 0 & \overline{4}\end{array}\right)$, respectively [30]. It is also apparent from Fig. 5 that crystallization of PTT at different temperatures (at least within the range studied) did not affect the positions of these characteristic peaks, indicating that the crystal modification of PTT did not change with varying $T_{\mathrm{c}}$. It has been determined that the crystal unit cell of PTT (based on WAXD results) is triclinic with axes $a=4.64 \AA, b=6.27 \AA$ and $c=18.64 \AA$, and angles $\alpha=98^{\circ}, \beta=90^{\circ}$, and $\gamma=112^{\circ}$, with an antichiral packing of molecules only along the $c$-axis [31]. The space group proposed for this crystal modification is $P \overline{1}$ [31].

Apart from the information regarding the crystal modification, the sharpness and broadness of the characteristic peaks shown in Fig. 5 also suggest that the apparent degree of crystallinity was an increase function with the $T_{\mathrm{c}}$ (within the $T_{\mathrm{c}}$ range studied). Quantitatively, the apparent degree of crystallinity $\chi_{\mathrm{c}}^{\mathrm{WAXD}}$ can be calculated from the relative ratio of the integrated intensities under the crystalline peaks $A_{\mathrm{c}}$ to the integrated total intensities $A_{\mathrm{t}}$, according to the following equation:

$\chi_{\mathrm{c}}^{\mathrm{WAXD}}=\frac{A_{\mathrm{c}}}{A_{\mathrm{t}}}=\frac{A_{\mathrm{c}}}{A_{\mathrm{c}}+A_{\mathrm{a}}} \in[0,1]$,

where $A_{\mathrm{a}}$ is the integrated intensities of the amorphous halo. Fig. 6 shows plot of the apparent degree of crystallinity of PTT samples isothermally crystallized at different temperatures (viz. the results were calculated from the raw WAXD patterns shown in Fig. 5). The apparent degree of crystallinity of PTT was found to be ca. $18.1 \%$ when it was crystallized at $182{ }^{\circ} \mathrm{C}$, and it was found to be ca. $28.4 \%$ at $206^{\circ} \mathrm{C}$, which is in agreement with a previous report that the apparent degree of crystallinity of melt-crystallized PTT samples was in the range of $15-30 \%$ [3]. It is qualitatively obvious that the WAXD degree of crystallinity of PTT increased with increasing $T_{\mathrm{c}}$ (at least within the $T_{\mathrm{c}}$ range studied).

\subsection{Melting behavior of PTT}

Fig. 7 contains successive DSC melting endotherms $\left(10^{\circ} \mathrm{C} \mathrm{min}{ }^{-1}\right)$ for PTT samples recorded after complete crystallization from the melt state at various crystallization temperatures ranging from 182 to $208^{\circ} \mathrm{C}$. Either double or triple-melting endotherms were observed. At temperatures below ca. $194{ }^{\circ} \mathrm{C}$, triple-melting endotherms were evident: the peaks were labeled as I, II, and III for low-, middle-, and high-temperature melting endotherms, respectively. The positions of both peaks I and II steadily increase with increasing crystallization temperature. However, the position of peak II was much less dependent on the crystallization temperature than that of peak I. Peak III disappears altogether when the crystallization temperature is greater than ca. $194{ }^{\circ} \mathrm{C}$. This triple-melting phenomenon has previously been reported [5]. The occurrence of peak I has been attributed to recrystallization during the re-heating process and peaks II and III to the melting of the primary crystallites of two populations of the lamellar stacks [5].

In a separate investigation about the multiple-melting behavior in isothermally crystallized PTT using DSC and

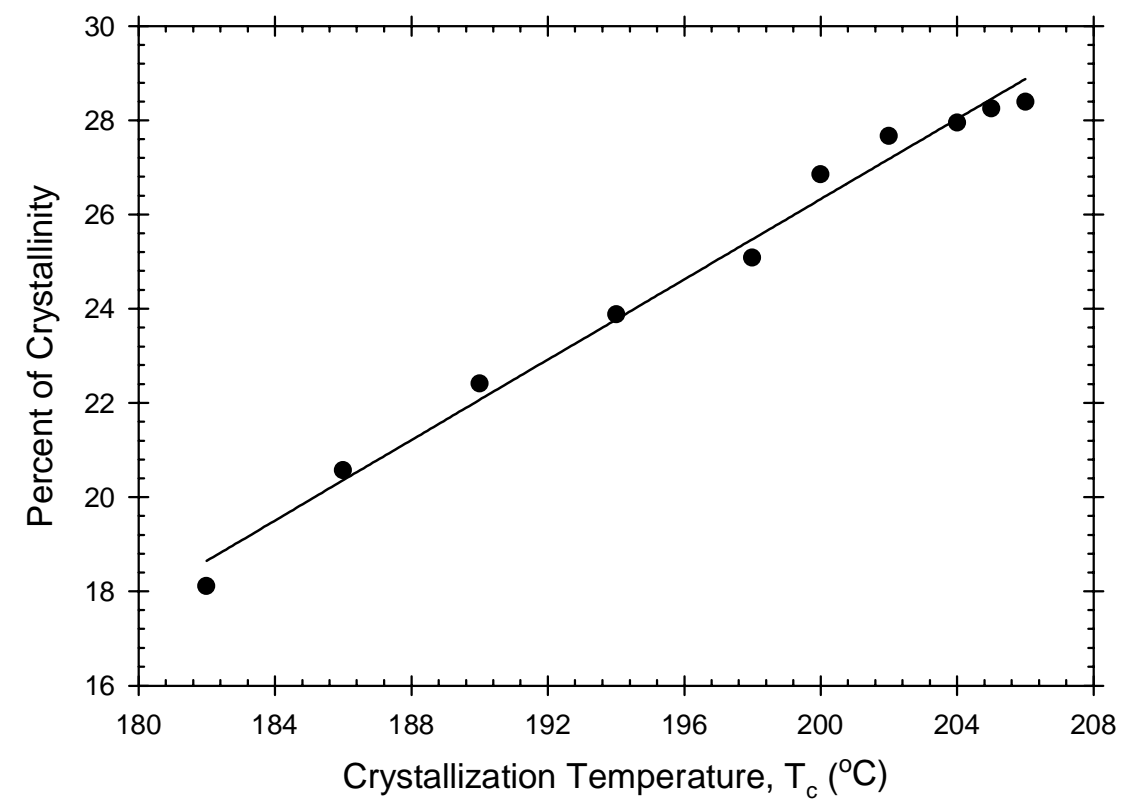

Fig. 6. Apparent degree of crystallinity for PTT samples (analyzed from the WAXD patterns) as a function of crystallization temperature. 


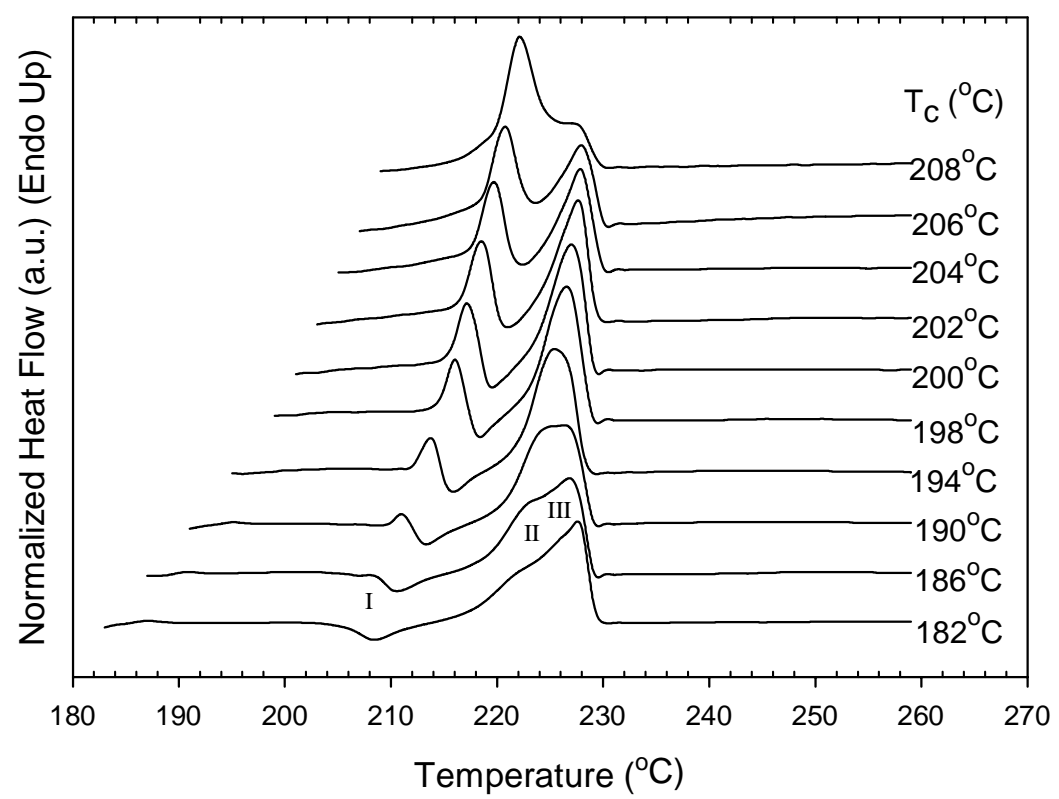

Fig. 7. Subsequent melting endotherms (recorded at $10^{\circ} \mathrm{C} \mathrm{min}^{-1}$ ) for PTT samples isothermally crystallized from the melt state at different crystallization temperatures. Peaks I, II, and III denotes the low-, middle-, and high-temperature melting endotherm, respectively.

WAXD techniques [32], it has been observed that the subsequent melting thermograms for PTT isothermally crystallized within the $T_{\mathrm{c}}$ range of $182-215^{\circ} \mathrm{C}$ exhibited triple (for $T_{\mathrm{c}}$ 's lower than ca. $192^{\circ} \mathrm{C}$ ), double (for $T_{\mathrm{c}}$ 's greater than ca. $192^{\circ} \mathrm{C}$ but lower than ca. $210^{\circ} \mathrm{C}$ ), or single (for $T_{\mathrm{c}}$ 's greater than ca. $210^{\circ} \mathrm{C}$ ) endothermic melting phenomenon. For the triple-melting phenomenon, it has been postulated that the occurrence of peak I was a result of the melting of the primary crystallites formed at $T_{\mathrm{c}}$, peak II was a result of the melting of recrystallized crystallites formed during a heating scan, and peak III was a result of the melting of the recrystallized crystallites of different stabilities which are formed during a heating scan.

\subsection{Determination of the equilibrium melting temperatures}

According to a theory derived by Hoffman and Weeks [33] (also known as the linear Hoffman-Weeks extrapolation), the equilibrium melting temperature $T_{\mathrm{m}}^{0}$, that is the melting temperature of infinitely thick crystallites, can be estimated by linear extrapolation of the apparent melting temperature $T_{\mathrm{m}}$ versus the crystallization temperature $T_{\mathrm{c}}$ data to the line $T_{\mathrm{m}}=T_{\mathrm{c}}$. Mathematically, this may be expressed by the equation:

$T_{\mathrm{m}}=\frac{T_{\mathrm{c}}}{2 \beta}+T_{\mathrm{m}}^{0}\left[1-\frac{1}{2 \beta}\right]$,

where $\beta$ is the "thickening ratio." In other words, $\beta$ indicates the ratio of the thickness of the mature crystallites $L_{\mathrm{c}}$ to that of the initial ones $L_{\mathrm{c}}^{*}$; therefore, $b=L_{\mathrm{c}} / L_{\mathrm{c}}^{*}$ is supposed to always be greater than or equal to 1 .

Fig. 8 shows a plot of the observed $T_{\mathrm{m}}$ versus $T_{\mathrm{c}}$ for PTT samples studied. Evidently, the observed $T_{\mathrm{m}}$ data displays a
Table 5

Estimated equilibrium melting temperatures for PET, PTT, and PBT according to linear and non-linear Hoffman-Week extrapolations, along with other fitting parameters

\begin{tabular}{|c|c|c|c|c|c|c|c|c|}
\hline \multirow[t]{2}{*}{ Polymer } & \multicolumn{4}{|l|}{ LHW } & \multicolumn{4}{|c|}{ NLHW } \\
\hline & $\begin{array}{l}T_{\mathrm{m}}^{0} \\
\left({ }^{\circ} \mathrm{C}\right)\end{array}$ & Slope & $\beta$ & $r^{2}$ & $\begin{array}{l}T_{\mathrm{m}}^{0} \\
\left({ }^{\circ} \mathrm{C}\right)\end{array}$ & $\beta^{\mathrm{m}}$ & $a$ & $r^{2}$ \\
\hline ET & 270.1 & 0.45 & 1.11 & 0.9932 & 323.9 & 1.00 & 1.17 & 0.99 \\
\hline PT & 243.6 & 0.60 & 0.82 & 0.9988 & 277.6 & 1.00 & 1.02 & 0.9979 \\
\hline PBT & 235.4 & 0.54 & 0.92 & 0.9826 & 262.3 & 1.00 & 1.47 & 0.9946 \\
\hline
\end{tabular}

linear correspondence to $T_{\mathrm{c}}$, at least within the temperature range of interest. The intersection of a least-squared line, fit to the data set for each sample, with the line $T_{\mathrm{m}}=T_{\mathrm{c}}$ provides the values of $T_{\mathrm{m}}^{0}$ The slope of the least-squared line, which equals $1 / 2 \beta$, can also be used to calculate the $\beta$ parameter (i.e. $\beta=0.5 \times$ slope $^{-1}$ ). These values, along with the $r^{2}$ parameter, for each best fit are reported in Table 5 . Using the LHW procedure, the $T_{\mathrm{m}}^{0}$ values for PET, PTT, and PBT were evaluated to be ca. $270.1,243.6$ and $235.4^{\circ} \mathrm{C}$, respectively. The $T_{\mathrm{m}}^{0}$ values for PET have been reported to be ca. 280 [34], 285 [35], and $291{ }^{\circ} \mathrm{C}$ [27], for PTT to be ca. 237 [36], 244 [37], 245 [38], and $248^{\circ} \mathrm{C}$ [2], and for PBT to be ca. 235 [35], 244 [39] and $245^{\circ} \mathrm{C}$ [36], respectively.

Although an explanation for the non-linearity in the observed $T_{\mathrm{m}}-T_{\mathrm{c}}$ data over a wide range of the temperature had previously been offered [40], a new extrapolative procedure to determine the $T_{\mathrm{m}}^{0}$ value of a semi-crystalline polymer based on the observed $T_{\mathrm{m}}-T_{\mathrm{c}}$ data in which the observed $T_{\mathrm{m}}$ data is taken from samples crystallized at different temperatures but with the same a priori lamellar thickening coefficient has recently been reported [41]. Derived based on 


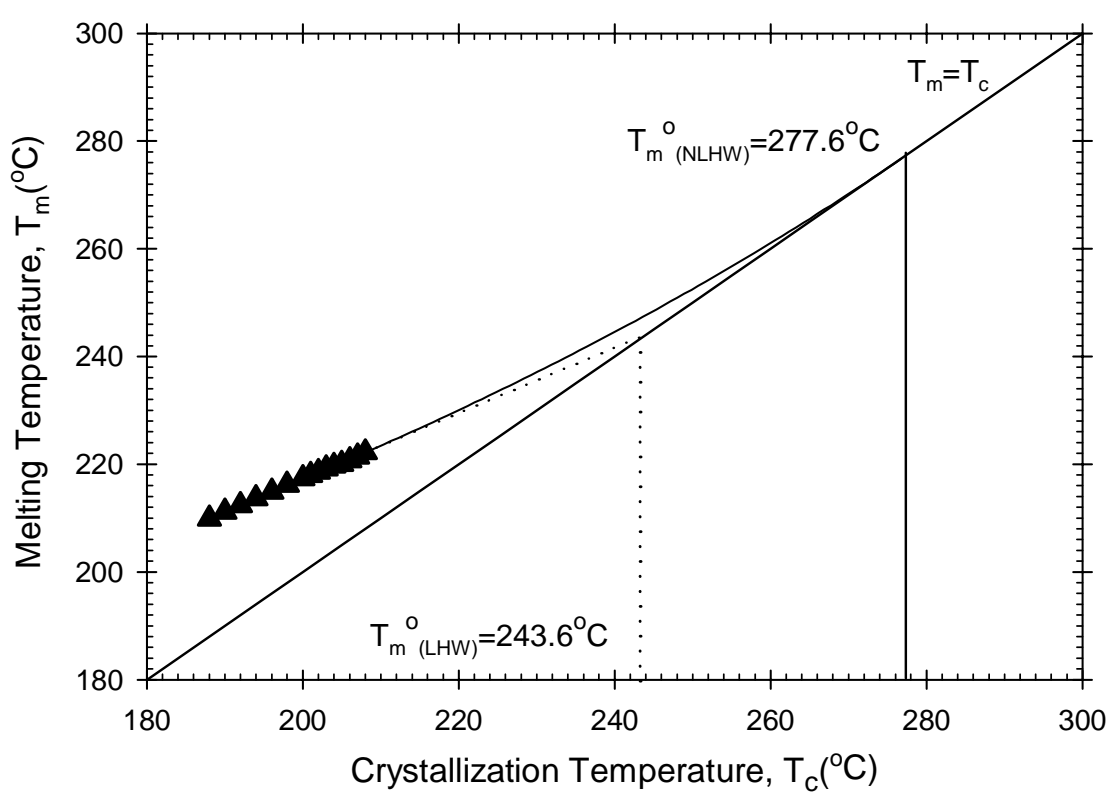

Fig. 8. Observed melting temperature of the primary crystallites as a function of crystallization temperature for PTT, shown along with the linear Hoffman-Weeks extrapolation (solid line) and the non-linear Hoffman-Weeks extrapolation (dotted line, calculated using $\beta^{\mathrm{m}}=1.00$ and $a=1.02$ ).

the Gibbs-Thomson equation $[22,42]$ and on the proposition of Lauritzen and Passaglia [43] on stem length fluctuation during chain folding, a new mathematical derivation was proposed [41], which states a relationship between the observed melting temperature and the corresponding crystallization temperature. This equation is hereafter called the non-linear Hoffmann-Weeks extrapolation, and is given in the form:

$\frac{T_{\mathrm{m}}^{0}}{T_{\mathrm{m}}^{0}-T_{\mathrm{m}}}=\beta^{\mathrm{m}} \frac{\sigma_{\mathrm{e}}^{1}}{\sigma_{\mathrm{e}}^{\mathrm{GT}}}\left[\frac{T_{\mathrm{m}}^{0}}{T_{\mathrm{m}}^{0}-T_{\mathrm{c}}}+\frac{D_{2} \Delta H_{\mathrm{f}}^{0}}{2 \sigma_{\mathrm{e}}^{1}}\right]$, or in a simpler form:

$M=\beta^{\mathrm{m}} \frac{\sigma_{\mathrm{e}}^{1}}{\sigma_{\mathrm{e}}^{\mathrm{GT}}}(X+a)$,

where $\beta^{\mathrm{m}}$ is the thickening coefficient, $\sigma_{\mathrm{e}}^{\mathrm{GT}}$ is the basal interfacial free energy associated with nuclei of critical size including the extra lateral surface energy due to fold protrusion and the mixing entropy associated with stems of different lengths $\left(\sigma_{\mathrm{e}}^{\mathrm{GT}}\right.$ is the basal interfacial free energy from the Gibbs-Thomson equation $[22,42]), \sigma_{\mathrm{e}}^{1}$ is the interfacial energy associated with the formation of the basal plane of

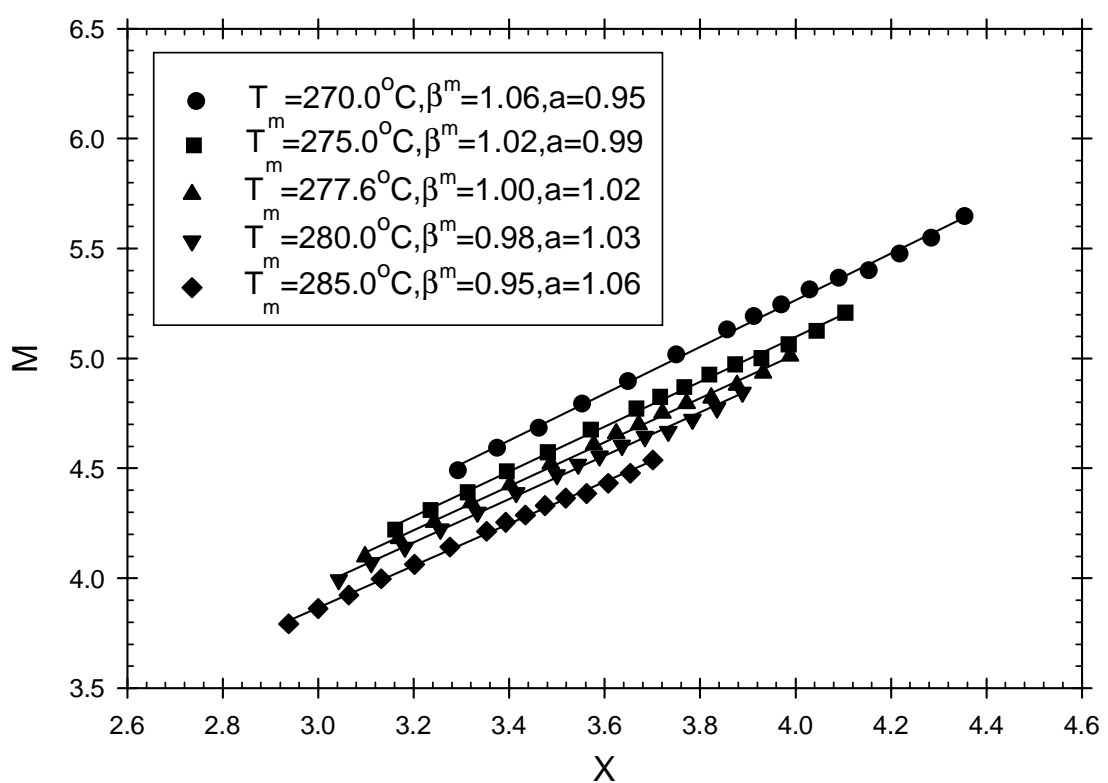

Fig. 9. Plots of the scaled observed melting temperature $M=T_{\mathrm{m}}^{0} /\left(T_{\mathrm{m}}^{0}-T_{\mathrm{m}}\right)$ against the scaled crystallization temperature $X=T_{\mathrm{m}}^{0} /\left(T_{\mathrm{m}}^{0}-T_{\mathrm{c}}\right)$ for various choice of the seeded equilibrium melting temperature $T_{\mathrm{m}}^{0}$ for the observed $T_{\mathrm{m}}-T_{\mathrm{c}}$ data of PTT. 
the initial crystals which can be estimated from the slope of a plot of the lamellar thickness versus the inversed degree of undercooling (i.e. $L_{\mathrm{c}}^{*}$ versus $\Delta T^{-1}$ ), $D_{2}$ is a constant, and all other parameters are the same as previously defined. It is worth noting that, for most cases, it is safe to assume that $\sigma_{\mathrm{e}}^{1} \approx \sigma_{\mathrm{e}}^{\mathrm{GT}}[41]$.

In order to apply Eq. (11) to analyze the observed $T_{\mathrm{m}}-T_{\mathrm{c}}$ data in real polymer systems, it is required that the observed $T_{\mathrm{m}}$ data be collected from samples crystallized at various $T_{\mathrm{c}}$ 's but having the same lamellar thickening coefficient $\beta^{\mathrm{m}}$ for each set of the observed $T_{\mathrm{m}}-T_{\mathrm{c}}$ data, corresponding values of $M$ and $X$ in Eq. (11) can be calculated for a given choice of $T_{\mathrm{m}}^{0}$ value. In the case where $\sigma_{\mathrm{e}}^{1}=\sigma_{\mathrm{e}}^{\mathrm{GT}}$, the "actual" equilibrium melting temperature $T_{\mathrm{m}}^{0}$ is taken as the seed $T_{\mathrm{m}}^{0}$ value which results in the plot of $M$ versus $X$ being a straight line with slope of unity (i.e. $\beta=1$ ) and the intercept of $a$ (i.e. $a=D_{2} \Delta H_{\mathrm{f}}^{0} / 2 \sigma_{\mathrm{e}}^{1}$ ). Fig. 9 shows the evolution of the $M$ versus $X$ plots for different choices of seed $T_{\mathrm{m}}^{0}$ value for PTT. According to the NLHW procedure, the $T_{\mathrm{m}}^{0}$ values for PET, PTT, and PBT were evaluated to be ca. 323.9, 277.6 and $262.3{ }^{\circ} \mathrm{C}$, respectively. The $T_{\mathrm{m}}^{0}$ value for PTT based on the NLHW procedure has previously been reported to be ca. $273^{\circ} \mathrm{C}$ [38], which is in excellent agreement with the obtained value. The marked difference in the $T_{\mathrm{m}}^{0}$ values obtained by the LHW and the NLHW procedure should be noted.

\section{Conclusions}

Differential scanning calorimetry has been used to investigate the overall kinetics of melt-crystallization of three different linear aromatic polyesters, namely PET, PTT, and PBT, under isothermal quiescent conditions and subsequent melting behavior. A non-linear multi-variable regression program was used to fit the experimental data obtained for each polymer at different crystallization temperatures to three different macrokinetic models, namely the Avrami, Tobin, and Malkin models. The crystallization kinetic parameters specific to each model were obtained from the best fits of the experimental data. It was found that the quality of each model for this analysis, judged by comparing the values of the $r^{2}$ parameter, in describing the isothermal crystallization data of these polyesters was in the following order: the Avrami, Malkin, and Tobin models.

All of the crystallization rate parameters (i.e. $t_{0.5}^{-1}, K_{\mathrm{a}}, K_{\mathrm{t}}$, and $C_{1}$ ) were found to be very sensitive to changes in the crystallization temperature. Within the crystallization temperature range studied (i.e. $182 \leq T_{\mathrm{c}} \leq 208^{\circ} \mathrm{C}$ ), the values of the rate parameters for these polyesters were all found to increase with decreasing temperature (or with increasing degree of undercooling), suggesting that these polyesters crystallize faster at low temperatures than that at high temperatures. It was also shown that all of the bulk crystallization rate parameters (i.e. $t_{0.5}^{-1}, K_{\mathrm{a}}, K_{\mathrm{t}}$, and $C_{1}$ ) have a finite, definable relationship with the crystallization temperature
$T_{\mathrm{c}}$ (or, to be exact, the degree of undercooling $\Delta T$ ), in which they can be described based on an equation similar to that previously proposed $[24,25]$ for the temperature dependence characteristic of the linear crystal growth rate of semi-crystalline polymers.

Wide-angle X-ray diffraction patterns obtained for PTT samples crystallized in the temperature range of $182-206^{\circ} \mathrm{C}$ showed seven characteristic peaks at the scattering angles $2 \theta$ of ca. $15.3,16.8,19.4,21.8,23.6,24.6$, and $27.3^{\circ}$, corresponding to the reflection planes of $(010),(0 \overline{1} 2),\left(\begin{array}{ll}0 & 1\end{array}\right)$,

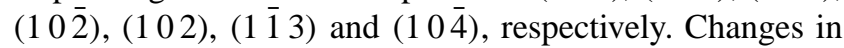
the crystallization temperature did not affect the diffraction pattern, suggesting that the crystal modification did not change with changes in the crystallization temperature (at least within the temperature range studied). The apparent degree of crystallinity $\chi_{\mathrm{c}}^{\mathrm{WAXD}}$ of these samples was also calculated and was found to increase with increasing crystallization temperature (i.e. from ca. $18.1 \%$ at $T_{\mathrm{c}}=182^{\circ} \mathrm{C}$ to $28.4 \%$ at $T_{\mathrm{c}}=206^{\circ} \mathrm{C}$ ).

The subsequent melting endotherms for PTT samples isothermally crystallized at temperatures ranging from 182 to $208^{\circ} \mathrm{C}$ exhibited either triple (at temperatures lower than ca. $194^{\circ} \mathrm{C}$ ) or double (at temperatures greater than ca. $194^{\circ} \mathrm{C}$ ) melting phenomenon. These peaks were denoted peaks I, II, and III for low-, middle-, and high-temperature melting endotherm, respectively. For triple-melting phenomenon, it was postulated that the occurrence of peak I was a result of the melting of the primary crystallites, peak II was a result of the melting of crystallites formed on recrystallization, and peak III was a result of the melting of reformed crystallites of different stabilities.

Lastly, analysis of the melting temperature of the primary crystallites according to the linear and non-linear HoffmanWeeks extrapolative methods to obtain the equilibrium melting temperatures $T_{\mathrm{m}}^{0}$ of these polyesters was conducted. According to the linear Hoffman-Weeks extrapolation, the $T_{\mathrm{m}}^{0}$ values for PET, PTT, and PBT were found to be ca. 270.1, 243.6 and $235.4^{\circ} \mathrm{C}$, respectively. According to the non-linear Hoffman-Weeks extrapolation, much higher values of ca. $323.9,277.6$ and $262.3^{\circ} \mathrm{C}$ were instead obtained.

\section{Acknowledgements}

The authors wish to thank Dr. Hoe H. Chuah and his co-workers of Shell Chemical Company (USA), Ltd. for supplying PTT and for their kind assistance with molecular weight measurements on all of the polyester resins received, Dr. Gi-Dae Choi and Soo-Min Lee of LG Chem (Korea) Ltd. for supplying of PBT, and Indo PET (Thailand) Ltd. for supplying of PET. PS acknowledges a grant provided by Chulalongkorn University through the Development Grants for New Faculty/Researchers. Partial support from the Petroleum and Petrochemical Technology Consortium and the Petroleum and Petrochemical College is gratefully acknowledged. 


\section{References}

[1] J.R. Whinfield, J.T. Dickson, Br. Pat. 578,079 (14 June 1946).

[2] J.M. Huang, F.C. Chang, J. Polym. Sci. Polym. Phys. 38 (2000) 934.

[3] H. Chuah, in: J. Scheirs, T. Long (Eds.), Modern Polyester, Wiley, New York, 2003 (Chapter 11).

[4] H. Chuah, Polym. Eng. Sci. 41 (2001) 308.

[5] W.T. Chung, W.J. Yeh, P.D. Hong, J. Appl. Polym. Sci. 83 (2002) 2426.

[6] J.N. Hay, M. Sabir, Polymer 10 (1969) 203.

[7] J.N. Hay, Br. Polym. J. 11 (1979) 137.

[8] A.N. Kolmogorov, Izvestiya Akad. USSR, Ser. Math. 1 (1937) 355.

[9] W.A. Johnson, K.F. Mehl, Trans. Am. Inst. Mining Met. Eng. 135 (1939) 416.

[10] M. Avrami, J. Chem. Phys. 7 (1939) 1103.

[11] M. Avrami, J. Chem. Phys. 8 (1940) 212.

[12] M. Avrami, J. Chem. Phys. 9 (1941) 177.

[13] U.R. Evans, Trans. Faraday Soc. 41 (1945) 365.

[14] M.C. Tobin, J. Polym. Sci. Polym. Phys. 12 (1974) 399.

[15] M.C. Tobin, J. Polym. Sci. Polym. Phys. 14 (1976) 2253.

[16] M.C. Tobin, J. Polym. Sci. Polym. Phys. 15 (1977) 2269.

[17] A.Y. Malkin, V.P. Beghishev, I.A. Keapin, S.A. Bolgov, Polym. Eng. Sci. 24 (1984) 1396.

[18] P. Supaphol, Thermochim. Acta. 370 (2001) 37.

[19] B. Wunderlich, in: Macromolecular Physics, vol. 2, Academic Press, New York, 1976, p. 132.

[20] P. Supaphol, N. Dangseeyun, P. Srimoaon, M. Nithitanakul, Thermochim. Acta., in press.

[21] H. Friedman, J. Polym. Sci. C6 (1964-1965) 183.
[22] J.D. Hoffman, G.T. Davis, J.I. Lauritzen Jr., in: N.B. Hannay (Ed.), Treatise on Solid State Chemistry, vol. 3, Plenum Press, New York, 1976 (Chapter 7).

[23] J.D. Hoffman, R.L. Miller, Polymer 38 (1997) 3151.

[24] S. Vyazovkin, N. Sbirrazzuoli, J. Phys. Chem. B107 (2003) 882.

[25] S. Vyazovkin, J. Comput. Chem. 18 (1997) 393.

[26] S. Vyazovkin, J. Comput. Chem. 22 (2001) 178.

[27] X.F. Lu, J.N. Hay, Polymer 42 (2001) 9423.

[28] H. Janeschitz-Kriegl, E. Ratajski, H. Wipel, Colloid Polym. Sci. 227 (1999) 217.

[29] P. Supaphol, J.E. Spruiell, J. Macromol. Sci. Phys. 39 (2000) 257.

[30] B. Wang, Y.C. Li, J. Hanzlicek, S.Z.D. Cheng, P.H. Gail, J. Grebowicz, R.M. Ho, Polymer 42 (2001) 7171.

[31] I.J. Desborough, I.H. Hall, J.Z. Neisser, Polymer 20 (1979) 419.

[32] P. Srimoaon, N. Dangseeyun, P. Supaphol, Eur. Polym. J., submitted for publication.

[33] J.D. Hoffman, J.J. Weeks, J. Res. Natl. Bur. Stand. A66 (1962) 13.

[34] P.J. Phillips, H.T. Tseng, Macromolecules 22 (1989) 1649.

[35] B. Wunderlich, in: Thermal Analysis, Academic Press, New York, 1990.

[36] M. Pyda, A. Boller, J. Grebowicz, H. Chuah, B.V. Lebedev, B. Wunderlich, J. Polym. Sci. Polym. Phys. 36 (1998) 2499.

[37] Y.H. Kim, K.J. Kim, K.M. Lee, J. Kor. Fiber Soc. 34 (1997) 860.

[38] P.-L. Wu, E.M. Woo, J. Polym. Sci. Polym. Phys. 40 (2002) 1571.

[39] J. Runt, D.M. Miley, X. Zhang, K.P. Gallangher, K. McFeathers, J. Fishburn, Macromolecules 25 (1992) 1929.

[40] R.G. Alamo, B.D. Viers, L. Mandelkern, Macromolecules 28 (1995) 3205.

[41] H. Marand, J. Xu, S. Srinivas, Macromolecules 31 (1998) 8219.

[42] R.G. Brown, R.K. Eby, J. Appl. Phys. 35 (1964) 1156.

[43] J.I. Lauritzen, E. Passaglia, J. Res. Natl. Bur. Stand. A71 (1967) 261. 